\title{
Remediation of TRU-Contaminated Soil by Aqueous Phase Leaching and Coprecipitation
}

\author{
Jae-Ho Lee \\ G. P. Martins \\ J. R. Weidner
}

Published September 1992

\author{
Idaho National Engineering Laboratory \\ EG\&G Idaho, Inc. \\ Idaho Falls, Idaho 83415
}

\author{
Prepared by \\ Colorado School of Mines \\ Department of \\ Metallurgical and Materials Engineering \\ Golden, Colorado 80401 \\ Subcontract No. C91-133260
}

Prepared for the

U.S. Department of Energy

Office of Environmental Restoration and Waste Management

Under DOE Idaho Fleld Office

Contract DE-AC07-761D01570 
Remediation of TRU-Contaminated Soil by Aqueous Phase Leaching and Coprecipitation

EGG-WTD-10429

Prepared by:
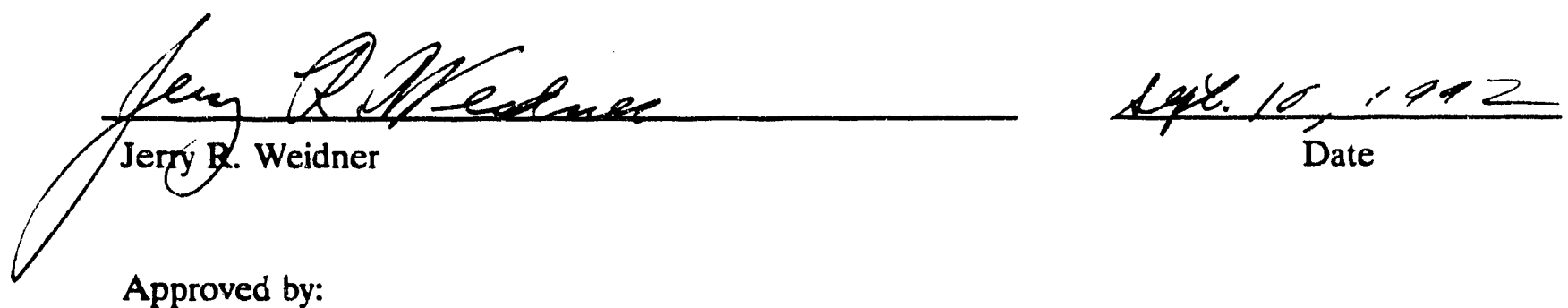

Approved by:
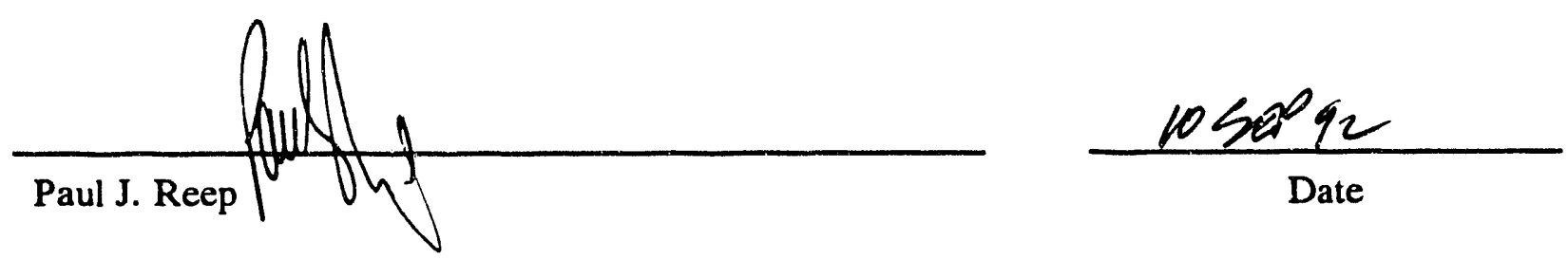


\section{ABSTRACT}

Chemical leaching studies were carried out on transuranic (TRU) waste contaminated ( $\approx 882 \mathrm{pCi} / \mathrm{gm}$ ) soil samples that were collected near the 903 Pad at the Rocky Flats Plant, Colorado. The studies were conducted in the research facilities of the Department of Metallurgical and Material Engineering, Colorado School of Mines.

The solvents studied were hydrochloric, sulfuric, and nitric acids in the concentration range of $10^{-2}$ to 1.0 molar. Solid to liquid ratios were $1: 2$ and $1: 8$. The soil size range was 75 to $150 \mu \mathrm{m}$.

Agitation-leach experiments having a 4 hour duration produced TRU extractions in the 65 to $85 \%$ range. TRU extraction by percolation leaching for 48 hours was about $75 \%$. Soil losses were less than $5 \%$ when percolation leaching was used and appeared to be primarily the organic component of the soil. No significant differences were observed among the acids used.

Removal of the TRU ions from the leachate was achieved by adding $\mathrm{NaOH}$ to change the solution to $\mathrm{pH}$ 7. The TRU ions were concentrated in the resulting precipitate. The concentration

of TRU ions remaining in the leachate was below the detection limit of the radioactive counting system used. 


\section{CONTENTS}

ABSTRACT $\ldots \ldots \ldots \ldots \ldots \ldots \ldots \ldots \ldots \ldots \ldots \ldots \ldots \ldots \ldots \ldots \ldots$

1. BACKGROUND AND SUMMARY $\ldots \ldots \ldots \ldots \ldots \ldots \ldots \ldots \ldots \ldots \ldots$

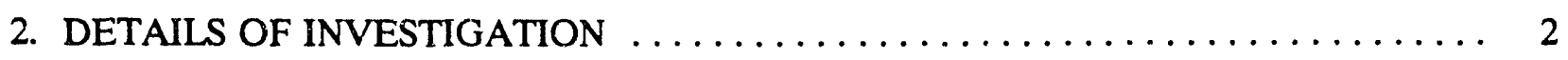

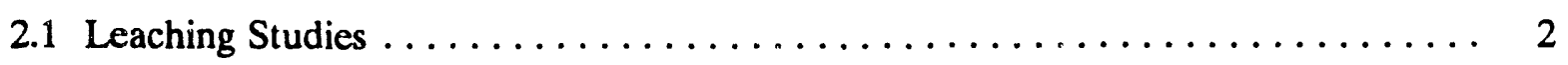

2.1.1 Laboratory-Scale Leach Systems . . . . . . . . . . . . . . 2

2.1.2 Preliminary Runs-Procedures, Observations, Results and Conclusions .... 6

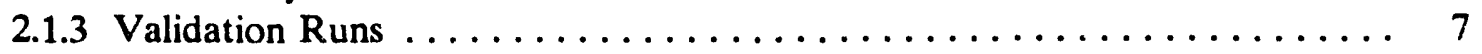

2.2 Coprecipitation/Adsorption Studies $\ldots \ldots \ldots \ldots \ldots \ldots \ldots \ldots \ldots \ldots \ldots \ldots \ldots \ldots \ldots \ldots \ldots$

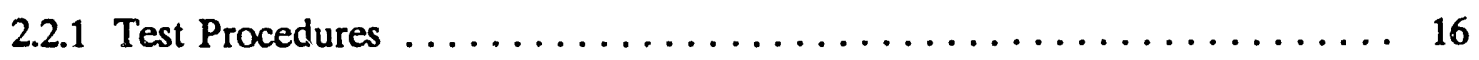

2.2.2 Preparation of Amorphous Iron Oxyhydroxide $\ldots \ldots \ldots \ldots \ldots \ldots \ldots \ldots$

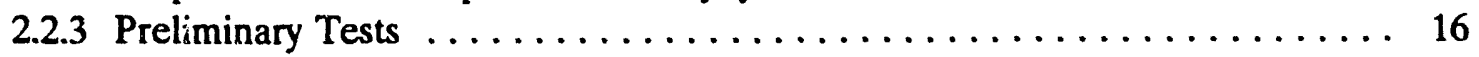

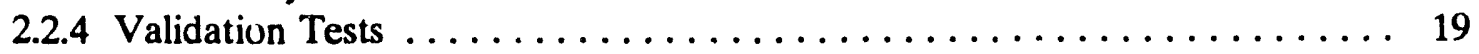

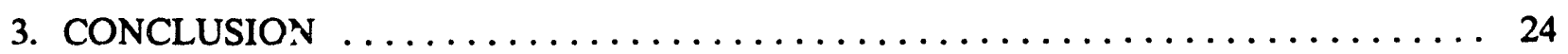

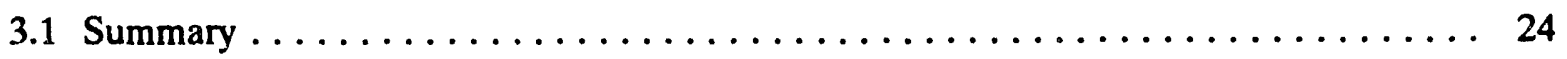

3.2 Conclusions and Recommendations $\ldots \ldots \ldots \ldots \ldots \ldots \ldots \ldots \ldots \ldots \ldots \ldots \ldots \ldots \ldots \ldots \ldots$

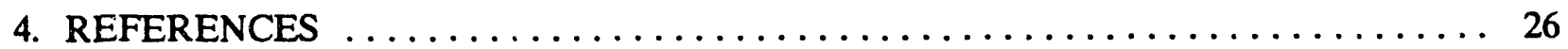

Appendix A-Amorphous Iron Oxyhydroxide Characterization $\ldots \ldots \ldots \ldots \ldots \ldots \ldots$ A-1

\section{FIGURES}

1. Schematic of percolation leach system $\ldots \ldots \ldots \ldots \ldots \ldots \ldots \ldots \ldots \ldots$

2. Schematic of test-tube agitation leach system $\ldots \ldots \ldots \ldots \ldots \ldots \ldots \ldots \ldots$

3. Schematic of large agitation-leach vessel $\ldots \ldots \ldots \ldots \ldots \ldots \ldots \ldots \ldots \ldots$

4. Standardized count rates for 30 minute test-tube agitation-leach depicting the effects of acid type and temperature. The hatched bar is for $20^{\circ} \mathrm{C}$, and the shaded bar is for $50^{\circ} \mathrm{C}$. Initial $\mathrm{pH}\left(20-25^{\circ} \mathrm{C}\right)$ is in brackets with final values to the right $\ldots \ldots \ldots \ldots$ 
5. Standardized count rates for 60 minute test-tube agitation-leach depicting the effects of acid type and temperature. The hatched bar is for $20^{\circ} \mathrm{C}$, and the shaded bar is for $50^{\circ} \mathrm{C}$. Initial $\mathrm{pH}\left(20-25^{\circ} \mathrm{C}\right)$ is in brackets with final values to the right $\ldots \ldots \ldots \ldots$

6. Standardized count rates for test-tube agitation-leach at $20^{\circ} \mathrm{C}$ depicting the effects of acid type and leach duration. The hatched bar is for 30 minute duration, and the shaded bar is for 60 minute duration. Initial $\mathrm{pH}\left(20-25^{\circ} \mathrm{C}\right)$ is in brackets with final

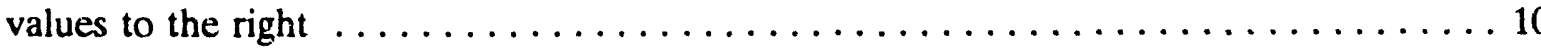

7. Standardized count rates for test-tube agitation-leach at $50^{\circ} \mathrm{C}$ depicting the effects of acid type and leach duration. The hatched bar is for 30 minute duration and the shaded bar is for 60 minute duration. Initial $\mathrm{pH}\left(20-25^{\circ} \mathrm{C}\right)$ is in brackets with final

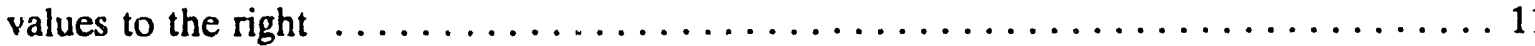

8. Standardized count rate and TRU extraction versus time for agitation-leach with $\mathrm{HNO}_{3}$ at $50^{\circ} \mathrm{C}$ and for three acid concentration levels. Solids to liquid ratio: $1 / 8$ (11 wt\%

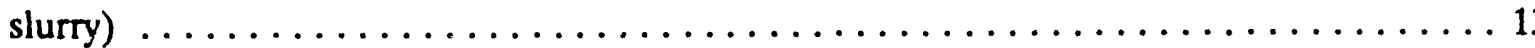

9. Standardized count rate and TRU extraction versus time for agitation-leach with $\mathrm{HNO}_{3}$ at $50^{\circ} \mathrm{C}$. Shaded band shows range of TRU extractions achieved with $1 \mathrm{M}$ and $0.5 \mathrm{M}$ lixiviants. Variability of TRU content of soil samples attributed to the behavior manifested

10. SEM photomicrographs comparing two (quartz) particles with similar morphological feature in (a) unleached soil and (b) the leached soil $\ldots \ldots \ldots \ldots \ldots \ldots \ldots \ldots$

11. SEM photomicrographs comparing two (clay) particles with similar morphological feature in (a) unleached soil and $(b)$ the leached soil $\ldots \ldots \ldots \ldots \ldots \ldots \ldots \ldots \ldots \ldots \ldots \ldots$

12. Leached treatment flow chart. Ambient temperature $\left(22-25^{\circ} \mathrm{C}\right)$ operation. Four milliliters leachate treated for each flow-chart component: $A-B_{1} ; A-B_{1}-C_{1} ; A-B_{2}-C_{2} \ldots 20$

13. Coprecipitation/adsorbent $\left(\mathrm{Fe}_{2} \mathrm{O}_{3} \cdot \mathrm{H}_{2} \mathrm{O}\right.$-am) performance. Relative TRU-content of

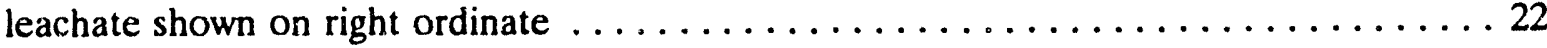

14. Coprecipitation/adsorbent $\left(\mathrm{Fe}_{2} \mathrm{O}_{3} \cdot \mathrm{H}_{2} \mathrm{O}\right.$-am $)$ performance. Relative TRU-content of

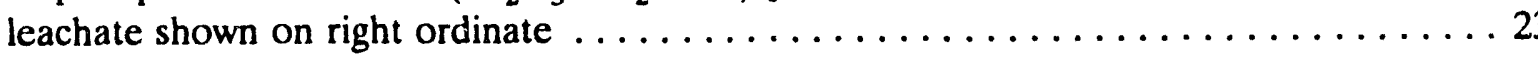

\section{TABLE}

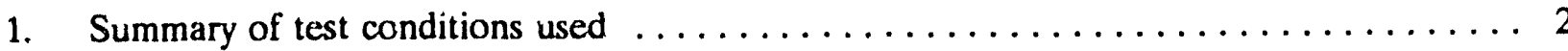




\section{Remediation of TRU-Contaminated Soil by Aqueous Phase Leaching and Coprecipitation}

\section{BACKGROUND AND SUMMARY}

The Colorado School of Mines, Department of Metallurgical and Materials Engineering, received eighteen 1-gal. cans of transuranic (TRU) waste contaminated scil ( $\approx 900 \mathrm{pCi} / \mathrm{gm}$ ) from the Rocky Flats Plant, Colorado. The soil samples were collected by Rocky Flats personnel about 150 yards southeast of the $903 \mathrm{Pad}^{\mathrm{a}}$ The school also received about $35 \mathrm{~kg}$ of an uncontaminated soil grab sample from the Idaho National Engineering Laboratory (INEL). The INEL sample was collected from the Lost River Spreading Area-A, an area immediately outside tr e Radioactive Waste Management Complex (RWMC) serving as a source of soil fill for the RWMC. The chemical, physical, and mineralogical properties of these soils are described in the characterization study.

Aqueous leaching tests were conducted on samples from the batch of TRU-contaminated soil from Rocky Flats. The as-received batch, selected on the basis of its low level of radioactive contamination $(<1000 \mathrm{pCi} / \mathrm{g})$, had been previously characterized. ${ }^{1}$ Three lixiviants were investigated-hydrochloric, sulfuric, and nitric acids. Subsequently, an adsorption/coprecipitation technique was investigated as a means of decontaminating the leachate. The principle of the technique is based on precipitating the iron contained in the leachate and/or the addition of ironoxyhydroxide adsorbent to the leachate. The $\mathrm{pH}$ of the leachate was adjusted by sodium hydroxide addition. This report contains the results of the investigation conducted.

The analyses were performed in the research laboratories of the Department of Metallurgical and Materials Engineering, Colorado School of Mines, under the supervision of Dr. G. P. Martins. The precision and accuracy of the data are expected to be excellent and according to standard research laboratory practice. The procedures are equivalent to Environmental Protection Agency (EPA) Analytical Level II.

a. Private communication between Dr. Michael Litaor and Dr. J. R. Weidner, June 1991. 


\section{DETAILS OF INVESTIGATION}

The two components of the work conducted are reported in this section. Results are provided for (a) leaching behavior and TRU extraction-versus-time progress and (b) TRU coprecipitation/ adsorption characteristics for selected leachates and TRU rejection from these leachates.

\subsection{Leaching Studies}

Three lixiviants were investigated-hydrochloric, sulfuric, and nitric acids. All tests were conducted with samples of Rocky Flats soil with particle sizes in the range 75 to $150 \mu \mathrm{m}(100 / 200 \mathrm{M})$. Concentrations of acids in the range $1 \mathrm{M}$ to $10^{-2} \mathrm{M}$ were used in the tests. Two solids to liquid ratios were used, 1:2 (33 wt\% slurry) and 1:8 (11 wt\% slurry). Both agitation and percolation solids/liquid contacting were employed. The (relative) extraction performance was assessed by radioactive counting on the leached solids (this was subsequently abandoned as being unreliable) and on the leachates. These details are summarized in Table 1.

\subsubsection{Laboratory-Sicale Leach Systems}

Schematics of the laboratory-scale leach systems are shown in Figures 1 through 3.

1. The percolation leach system is shown in Figure 1. The liquid capacity of each Pyrex vessel is approximately $25 \mathrm{cc}$. A medium pore Pyrex frit is fused to the bottom section of each vessel. A peristaltic pump is used to circulate the lixiviant in the systemapproximately $600 \mu \mathrm{l} / \mathrm{min}$. Liquid samples were collected by pumping from the reservoir vessel. A corresponding volume of lixiviant (acid) was then replaced in the system.

2. The agitation-leach system shown in Figure 2 was used to provide for "rapid" assessment of the TRU-extractions for 30 and 60 minutes leach-times. For each run, $2 \mathrm{~g}$ of solid and $4 \mathrm{~mL}$ of lixiviant were transferred to the empty test tube (soil/liquid ratio, 1:2). This slurry was agitated by the motor-driven stirrer rod with a triangular eccentric section at its end. Both ambient temperature $\left(22-25^{\circ} \mathrm{C}\right)$ and $50^{\circ} \mathrm{C}$ thermostated runs were conducted. The test-tube was removed from the water jacket and centrifuged, after which most of the supernatant was decanted into a vial. Two milliliters of this solution were then withdrawn with a pipette and transferred to another vial for subsequent radioactive counting.

Table 1. Summary of test conditions used.

Acids

Acid concentration range

Solid/liquid ratio

Contacting

Solids (soil) size range

External performance analysis
$\mathrm{HCl}, \mathrm{H}_{2} \mathrm{SO}_{4}, \mathrm{HNO}_{3}$

$10^{-2}$ to $1.0 \mathrm{M}$

$1: 2(33 w t \%)$ and $1: 8$ (11 wt\%)

Agitation and percolation

75 to $150 \mu \mathrm{m}$

Radioactive counting on leachate 


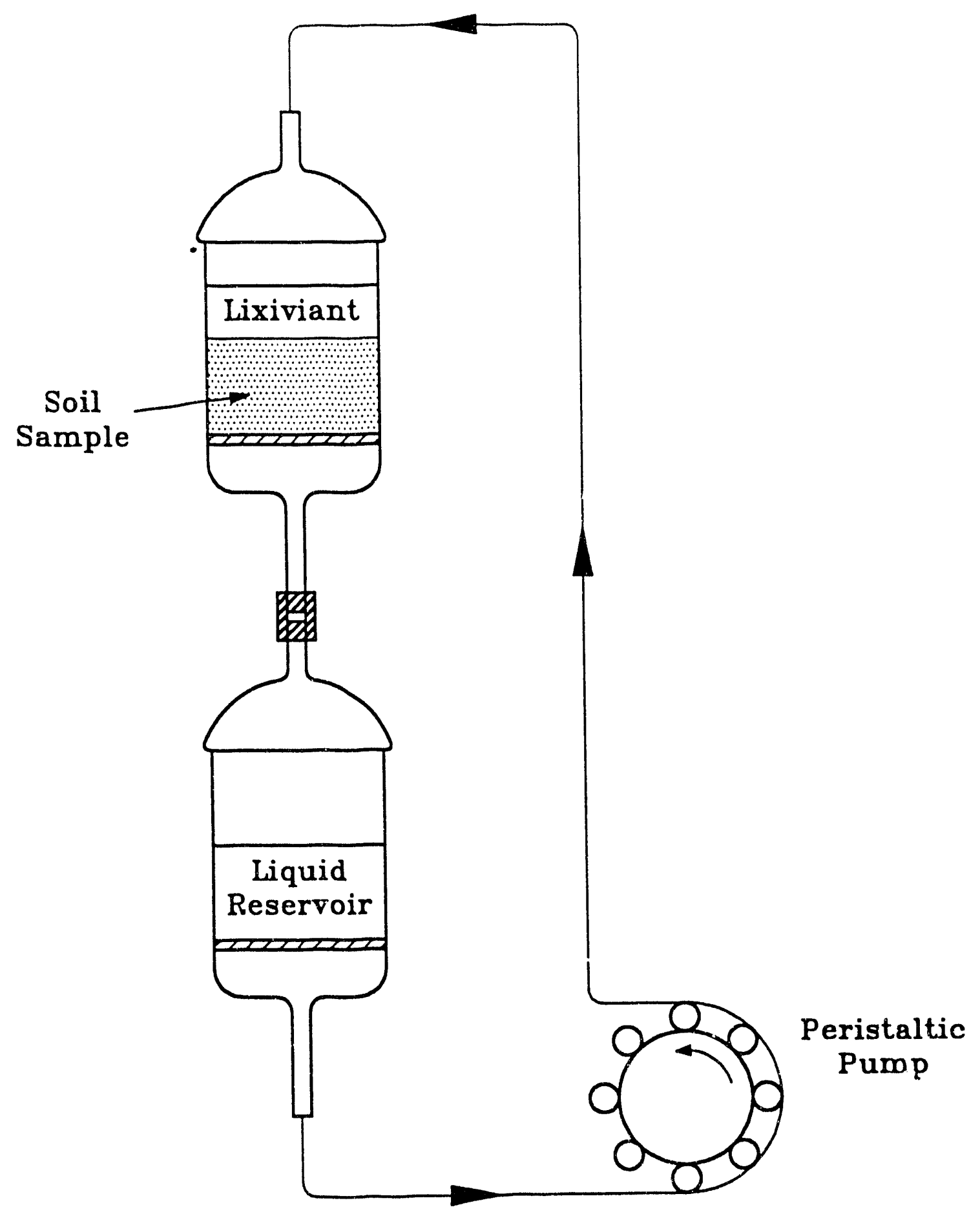

Figure 1. Schematic of percolation leach system. 


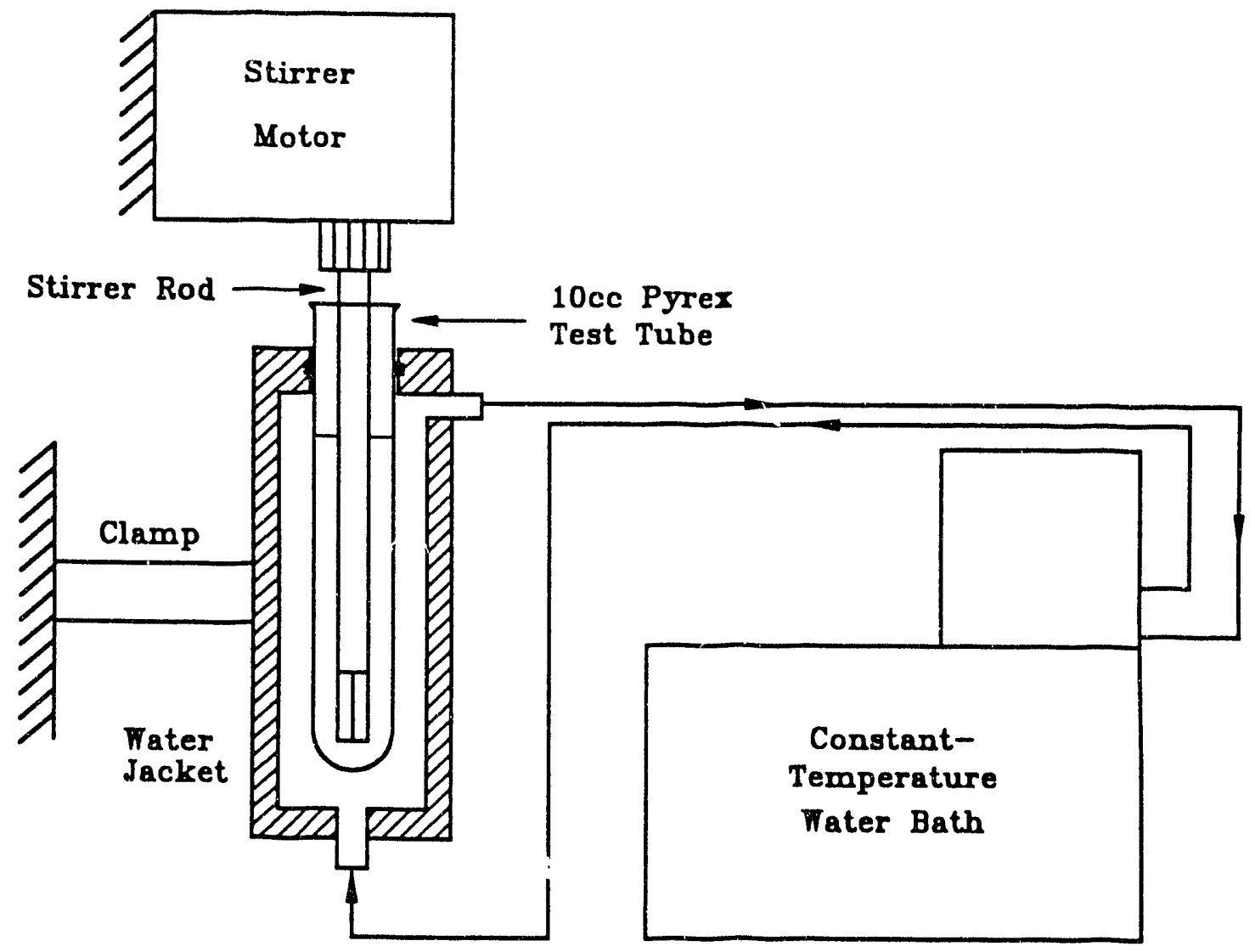

Figure 2. Schematic of test-tube agitation leach system. 


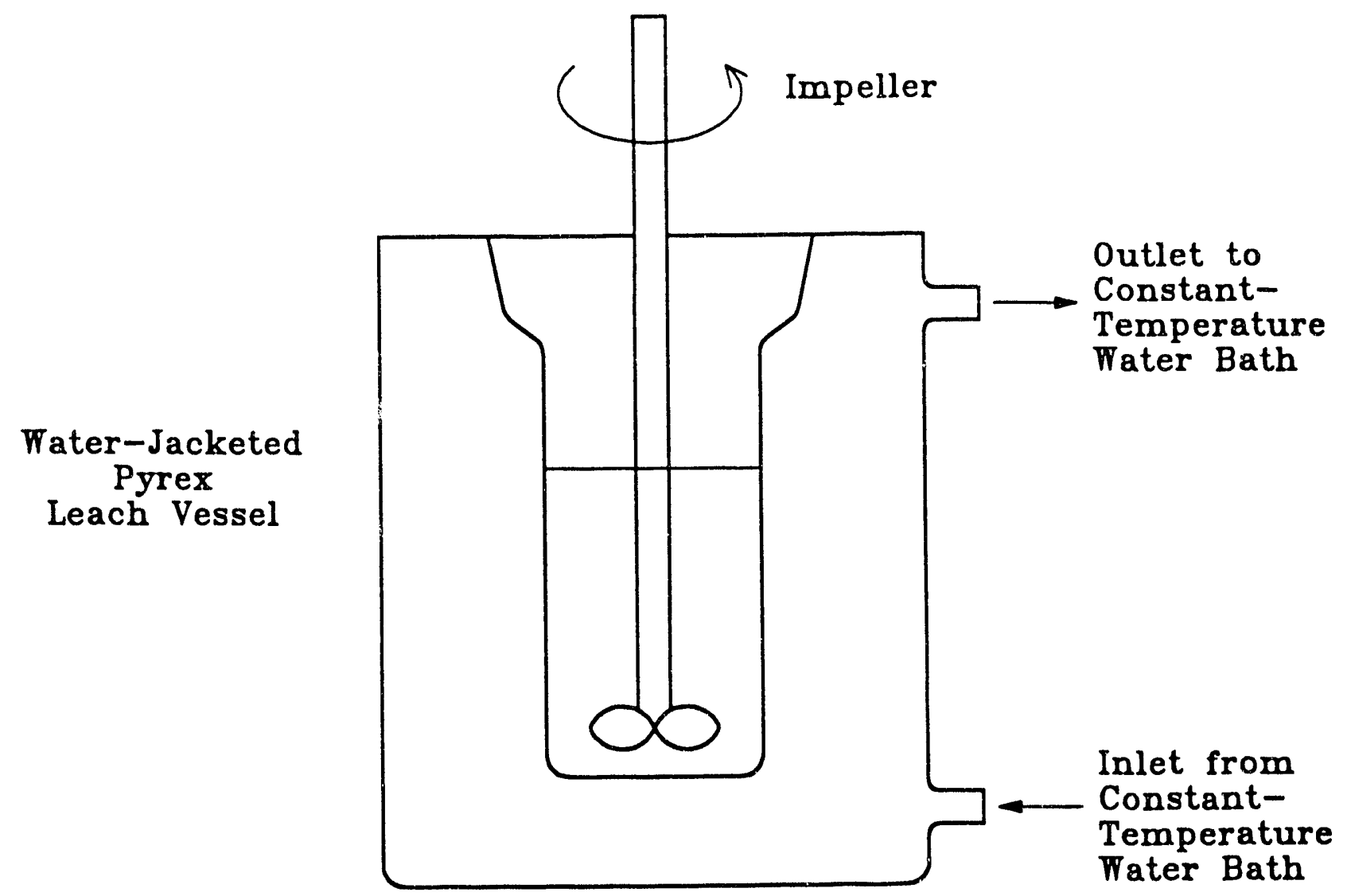

Figure 3. Schematic of large agitation-leach vessel. 
3. The system shown in Figure 3 is a larger version of the test-tube arrangement and was used to evaluate the leaching response for a smaller soil-to-liquid ratio (1:8). Leaching runs were usually conducted for 4 hours, and agitation was provided by a polyethylene marine-type impeller located close to the bottom of the leach-vessel section. This system was used for runs conducted at $50^{\circ} \mathrm{C}$. Approximately $100 \mathrm{~mL}$ of lixiviant were used for these runs. Samples were withdrawn from the system by allowing the slurry to settle for 2 minutes, after which $3 \mathrm{~mL}$ were extracted with a pipette, transferred to a test tube, and centrifuged. The supernatant was then decanted into an intermediate vial and from which $2 \mathrm{~mL}$ were withdrawn with a pipette for radioactive counting.

\subsubsection{Preliminary Runs-Procedures, Observations, Results, and Conclusions}

Two percolation runs and several test-tube agitation-leach runs were conducted first. The testtube agitation-leach runs allowed a broad spectrum of leaching performance results to be collected and subsequently analyzed. For the two percolation runs conducted, $10 \mathrm{~g}$ of soil were placed in the upper vessel (see Figure 1) and $30 \mathrm{~mL}$ of hydrochloric acid $(\mathrm{pH}=2.0)$ in the lower vessel. Also, this lixiviant contained potassium chloride at a concentration of $0.05 \mathrm{M}$. The reason for including potassium ion in the lixiviant was evidence indicated that this cation could play a role in altering the clay structure in the soil. The $\mathrm{pH}$ of the solution leaving the lower vessel was monitored by a combination $\mathrm{pH}$ electrode/flow-cell arrangement placed in the circuit. The analog output from the pH meter was then used as a control signal to a metering (peristaltic) pump to effect addition of hydrochloric acid solution $(\mathrm{pH}=0.3)$ to maintain the effluent $\mathrm{pH}$ at approximately 2.0 . The run lasted for 26 hours in one case and 24 hours in the other; final $\mathrm{pH}$ of the effluent solutions were 0.95 and 1.55 , respectively; acid additions were $30 \mathrm{~mL}$ and $10.5 \mathrm{~mL}$, respectively. It is seen that the $\mathrm{pH}$ control-system did not function satisfactorily and was not used in later runs. It was apparent that significant higher acid concentration would be required to effect practical extractions of TRU components from the soil, and $\mathrm{pH}$ control was no longer a consideration. Radioactive counting on the leached soil were conducted, similar to that for the characterization studies. ${ }^{1}$ A $15-\mathrm{mm}$ diameter $\times 6-\mathrm{mm}$ thick pellet of the leached soil was prepared by pressing in a punch and die system; the pellet was placed in a well-type scintillation counter in conjunction with a multichannel analyzer; the analysis was conducted at the characteristic erergy for ${ }_{95}^{241} \mathrm{AM}$, of $60 \mathrm{keV}$. The count rates recorded for the two cases were 61 and $73 \%$ relative to the unleached material, respectively, indicating that apparently 39 and $27 \%$ of the TRU components in the soil had been removed by leaching.

It was then decided that a broad spectrum of performance results could be obtained "rapidly" by using the leach system whose schematic is shown in Figure 2. For these tests, $2 \mathrm{~g}$ of soil and $4 \mathrm{~mL}$ of lixiviant were used. Three types of acids were used: $\mathrm{HCl}, \mathrm{H}_{2} \mathrm{SO}_{4}$, and $\mathrm{HNO}_{3}$ (potassium chloride was absent in these solutions). The range of concentrations were 0.01 to $0.5 \mathrm{M}$, with corresponding $\mathrm{pH}$ values (depending on the acid) of approximately 2 to 0.3 . A total of 20 runs was conducted, and for most of these, the leach temperature was $50^{\circ} \mathrm{C}$, since this temperature could be maintained consistently, compared to the ambient temperature that would vary between 20 to $25^{\circ} \mathrm{C}$.

The gross features of the performance results are condensed below:

1. No effect of the acid type was apparent. The extraction of TRU components, for a specific time of leaching ( 30 or 60 minutes), could be correlated to the $\mathrm{pH}$ of the lixiviant. Lower $\rho \mathrm{H}$ resulted in higher apparent extractions. 
2. Apparent TRU extraction did not exceed $40 \%$. Also, there was no significant difference in extraction between the 30 and 60 minute runs.

3. Although there was an increased extraction at $50^{\circ} \mathrm{C}$ (compared to ambient temperature), it was modest.

4. It was discovered that, after centrifuging, approximately $30 \%$ of the leachate was held up in the leach residue. Consequently, it was decided to prepare the pressed pellet from the wet residue directly rather than first dry it. However, radioactive counting of this pellet produced a higher count-rate than the original unleached material. It became apparent that an alternative analysis scheme would be needed to assess the extraction performances obtained from the leaching tests. The analysis procedure was then modified so that radioactive counting was conducted, instead, on a fixed volume of leachate.

\subsubsection{Validation Runs}

2.1.3.1 Test-Tube Agitation-Leach. Once the analysis procedure using the leachate was established, several validation runs were conducted with the test-tube agitation leach system according to the procedures outlined in Section 2.1.1. The results of these tests that assessed the relative performance from the effects of (a) acid type, (b) temperature, and (c) leach duration are shown in Figures 4 through 7 . The acid concentration ir, ach case was $0.5 \mathrm{M}$. The "standardized" count rate is based on conducting radioactive counting on $2 \mathrm{~mL}$ of leachate and for a soil to lixiviant ratio of 1:2. Thus, for tests where, for example, a ratio of $1: 8$ was used, the count rate was corrected (multiplied by four) to convert back to the standard leach conditions.

For the 30 minutes duration leach (see Figure 4), the sulfuric-acid lixiviant produced the highest count rate of approximately $1.8 \mathrm{~Hz}$ at $50^{\circ} \mathrm{C}$, while for $\mathrm{HCl}$ and $\mathrm{HNO}_{3}$, the count rates were both $1.6 \mathrm{~Hz}$. At the lower temperature of $20^{\circ} \mathrm{C}$, the corresponding values are $1.25,1.05$, and $0.95 \mathrm{~Hz}$.

When the leach duration was increased to 60 minutes (see Figure 5), the effect of temperature did not appear to be significant when hydrochloric acid was used-count rates of 1.45 and $1.55 \mathrm{~Hz}$ at 20 and $50^{\circ} \mathrm{C}$, respectively. However, the effect of temperature is seen to be dramatic for the case of nitric acid, where count rates of 1.0 and $1.9 \mathrm{~Hz}$ at 20 and $50^{\circ} \mathrm{C}$, respectively, are achieved. Thus, the extraction is almost doubled. Also, nitric acid gave the highest extraction at $50^{\circ} \mathrm{C}$, compared to the other two acids. For sulfuric acid, the count rates at 20 and $50^{\circ} \mathrm{C}$ are 1.5 and $1.75 \mathrm{~Hz}$, respectively.

In Figure 6 and 7, the information contained in Figures 4 and 5 is recast to show the effects of leach duration at 20 and $50^{\circ} \mathrm{C}$. At $50^{\circ} \mathrm{C}$, Figure 7, the effect of leach duration is small except for nitric acid-count rates of $1.6 \mathrm{~Hz}$ for 30 minutes and $1.9 \mathrm{~Hz}$ for 60 minutes. At the lower temperature, $20^{\circ} \mathrm{C}$, Figure 6 , a count rate of $1.05 \mathrm{~Hz}$ for 30 minutes leach-duration is obtained for $\mathrm{HCl}$, and for 60 minutes leach-duration, the count rate increased to $1.45 \mathrm{~Hz}$. For sulfuric acid the count rate is $1.25 \mathrm{~Hz}$ for 30 minutes leach-duration and increases to $1.5 \mathrm{~Hz}$ for the longer-duration leach. Nitric acid produced the lowest count rates, 0.95 and $1.0 \mathrm{~Hz}$ for 30 minutes and for 60 minutes leach-durations, respectively. It is apparent that at the higher temperature, i.e., $50^{\circ} \mathrm{C}$, the effects of leach duration are not particularly significant, and although nitric acid and sulfuric acid gave the highest extractions, the variation between acid type is not dramatic. Consequently, since the second 


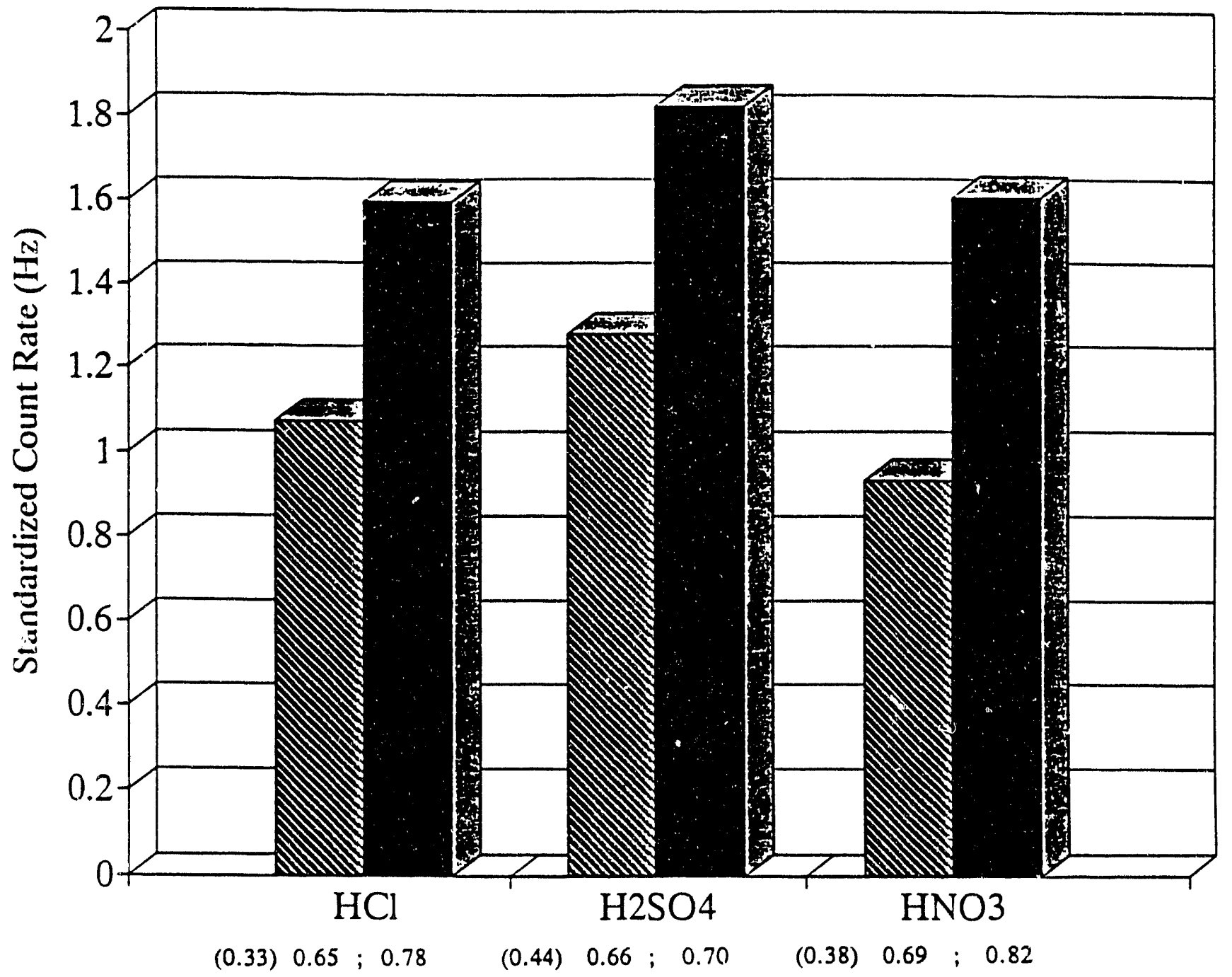

Figure 4. Standardized count rates for 30 minute test-tube agitation-leach depicting the effects of acid type and temperature. The hatched bar is for $20^{\circ} \mathrm{C}$, and the shaded bar is for $50^{\circ} \mathrm{C}$. Initial $\mathrm{pH}$ $\left(20-25^{\circ} \mathrm{C}\right)$ is in brackets with final values to the right. 


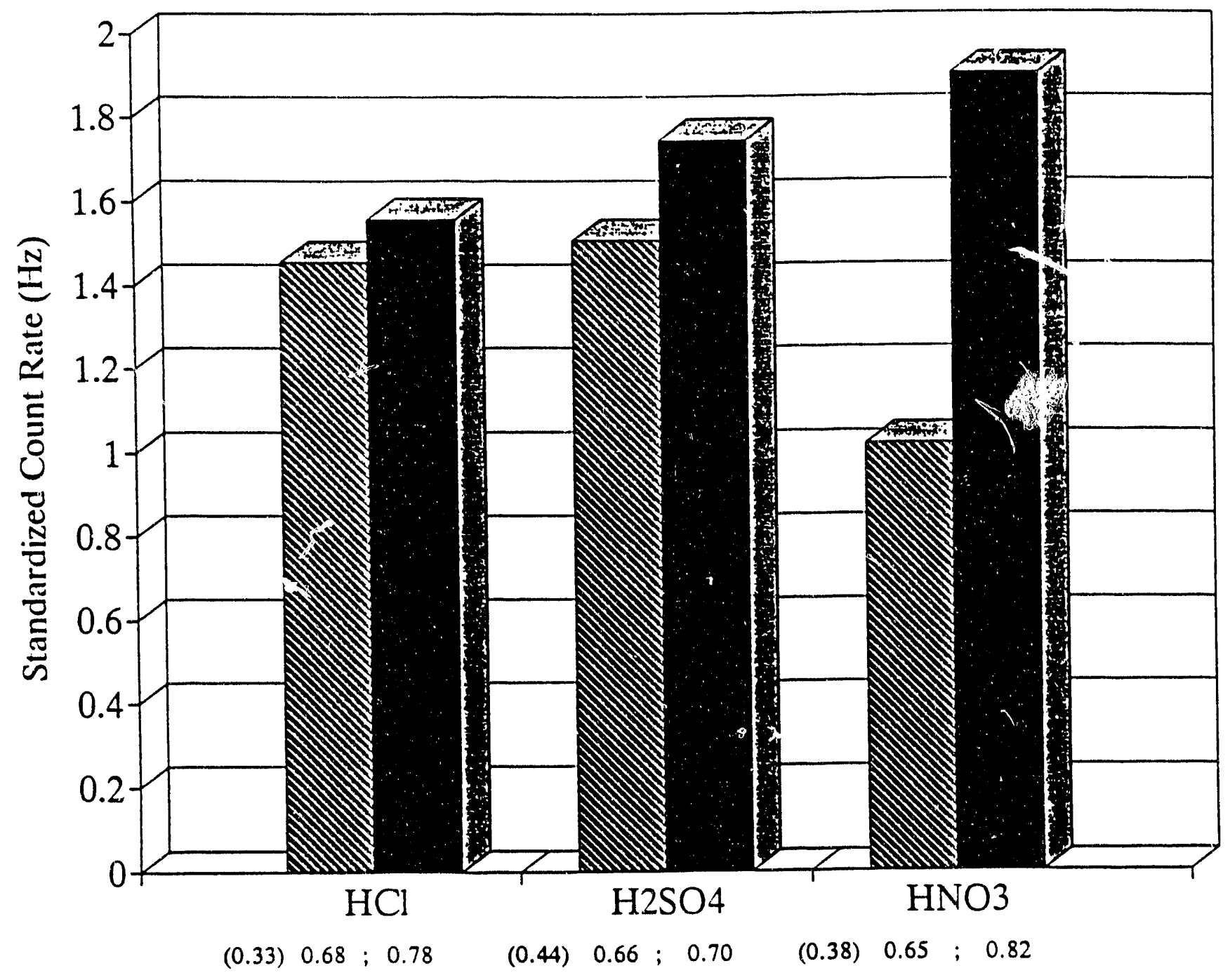

Figure 5. Standardized count rates for 60 minute test-tube agitation-leach depicting the effects of acid type and tempera?ure. The hatched bar is for $20^{\circ} \mathrm{C}$, and the shaded bar is for $50^{\circ} \mathrm{C}$. Initial $\mathrm{pH}$ $\left(20-25^{\circ} \mathrm{C}\right)$ is in brackits with final values to the right. 


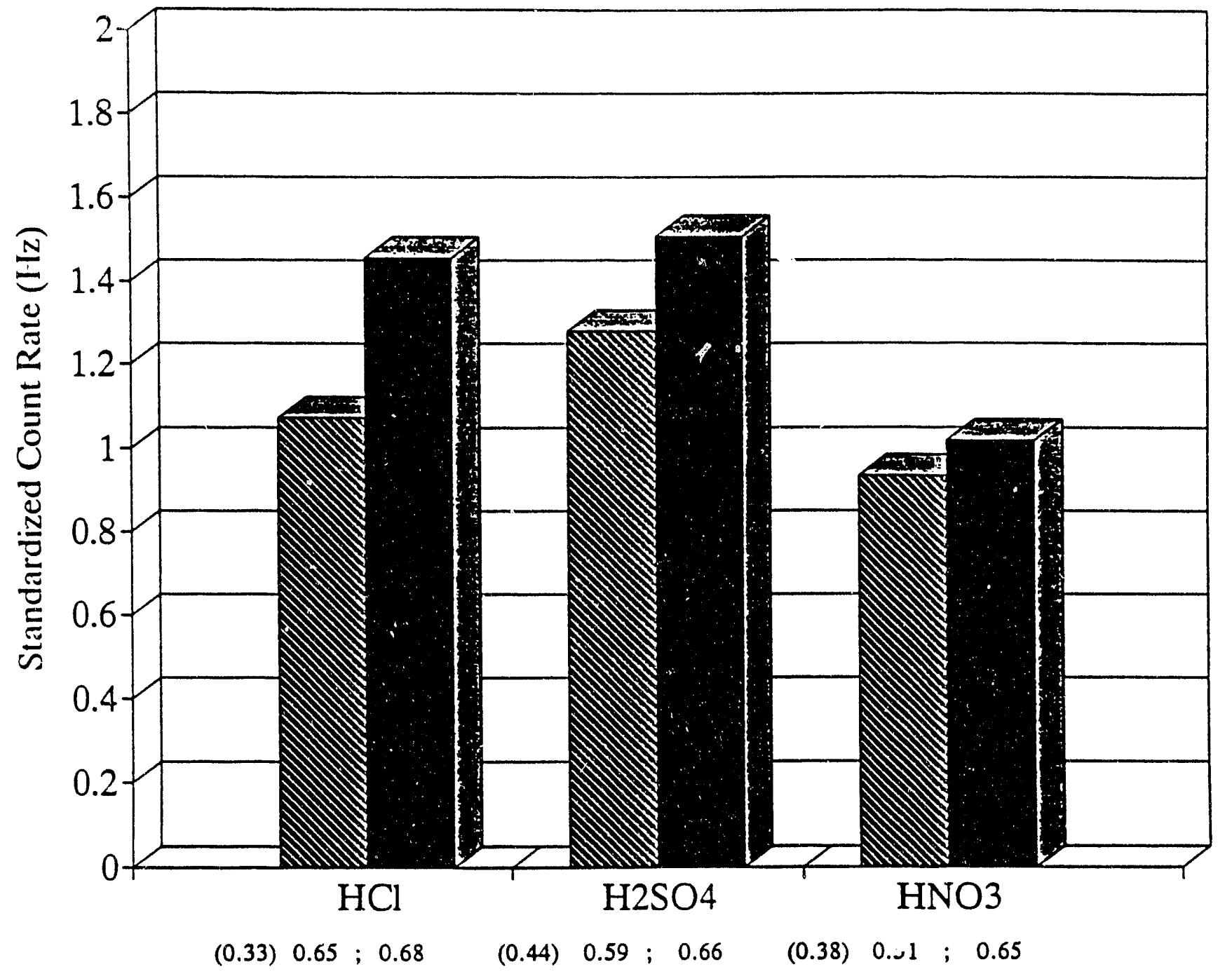

Figure 6. Standardized count rates for test-tube agitation-leach at $20^{\circ} \mathrm{C}$ depicting the effects of acid type and leach duration. The hatched bar is for 30 minute duration, and the shaded bar is for 60 minute duration. Initial $\mathrm{pH}\left(20-25^{\circ} \mathrm{C}\right)$ is in brackets with final values to the right. 


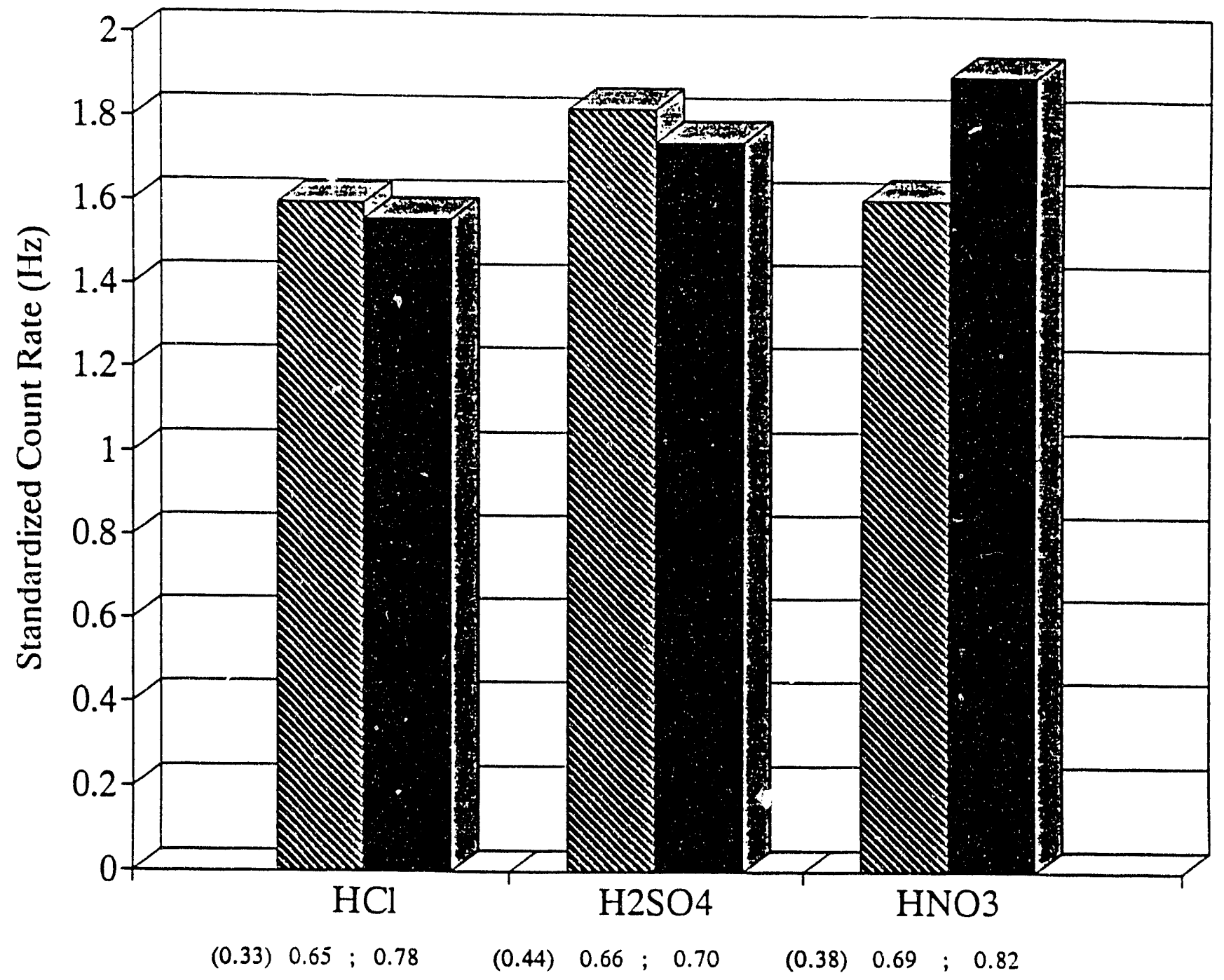

Figure 7. Standardized count rates for test-tube agitation-leach at $50^{\circ} \mathrm{C}$ depicting the effects of acid type and leach duration. The hatched bar is for 30 minute duration, and the shaded bar is for 60 minute duration. Initial $\mathrm{pH}\left(20-25^{\circ} \mathrm{C}\right)$ is in brackets with final values to the right. 
component of this investigation was to study the rejection of TRU component in the leachate to a precipitate/iron oxyhydroxide adsorbent, it was convenient to select the nitrate system instead of either the chloride or sulfate system. The reason for this selection is related to the preparation of the iron oxyhydroxide, for which the method of synthesis utilizes a nitrate system.

2.1.3.2 Assessment of Relative TRU Extraction. A $1 \mathrm{~g}$ sample of the unleached soil was digested in $5 \mathrm{~mL}$ of aqua regia. The resulting solution was analyzed by radioactive counting in a manner similar to that used for the leach tests. After standardization, the count rate was calculated and found to be $4.2 \pm 0.1 \mathrm{~Hz}$. Thus, if a leachate produced a standardized count rate equal to this value, the TRU extraction from the soil would be equivalent to $100 \%$. However, a nominal value of $4.0 \mathrm{~Hz}$ was selected, for convenience, to be equivalent to $100 \%$. This feature is included in plots of the results of the later validation runs, which are presented below.

2.1.3.3 Percolation Leach. On examining the results of the test-tube agitation runs presented above, it can be seen that the maximum standardized count rate was achieved with nitric acid at $50^{\circ} \mathrm{C}$. However, the value of $1.9 \mathrm{~Hz}$ corresponds to a TRU extraction of only $49 \%$. Furthermore, it was apparent that the extraction mechanism was not being limited by solids/liquid contact, after the first 60 minutes of leaching. Consequently, a long duration percolation-leach was conducted with the same lixiviant ( $1 \mathrm{M} \mathrm{HNO}_{3}$ ) and a solid to liquid ratio of 1:8 (11 wt\% slurry). The actual quantities were $5 \mathrm{~g}$ of soil and $40 \mathrm{~mL}$ of lixiviant. The as-received soil was pulverized in a ceramic vibrating mill to a particle size of $<400 \mathrm{M}(<30 \mu \mathrm{m})$. The run duration was 48 hours. The leachate recovered at this time indicated a standardized count rate of $3.9 \pm 0.1 \mathrm{~Hz}$. This corresponds to an extraction of approximately $93 \%$ (based on $4.2 \mathrm{~Hz} \equiv 100 \%$ ). However, a replicate run was conducted and resulted in a standardized count-rate of $3.1 \pm 0.1 \mathrm{~Hz}$, corresponding to only $74 \%$ extraction (based on $4.2 \mathrm{~Hz}=100 \%$ ).

2.1.3.4 Agitation-Leach. These test were conducted in the system with the schematic shown in Figure 3, and the results are displayed in Figure 8. A solids to liquid ratio of 1:8 was used similar to that used for the percolation leach. The actual quantities were $12 \mathrm{~g}$ of soil and $96 \mathrm{~mL}$ of lixiviant. In addition, three acid concentration levels were investigated $(1,0.5$, and $0.1 \mathrm{M})$, and the as-received soil was pulverized for one of the tests. The system was operated at $50^{\circ} \mathrm{C}$. The leaching behavior of the pulverized sample, and the as-received soil were similar during 4 hours of leaching. Approximately $60 \%$ TRU extraction was achieved during the first half hour. The increase in extraction beyond this period is small-10 percentage points increase to approximately $70 \%$. For a leach duration of 8 hours, approximately $75 \%$ extraction was realized, and after 14 hours the extraction had increased to only $78 \%$.

When the acid concentration level was decreased to half of the previous value $(0.5 \mathrm{M})$, the extraction was approximately 5\% lower during the first hour of leaching. After an elapsed time of 4 hours, the extraction obtained was $65 \%$ compared to $70 \%$ when $1 \mathrm{M}$ acid was used. As-received soil was used for this run, since no significant improvement in extraction was achieved for the comminuted sample.

Further decrease in the acid concentration level to $0.1 \mathrm{M}$, resulted in a significant attenuation in leaching behavior. After half an hour had elapsed, $15 \%$ extraction was obtained. This increased to $20 \%$ when 1 hour had elapsed, and after 8 hours the extraction was $25 \%$. 


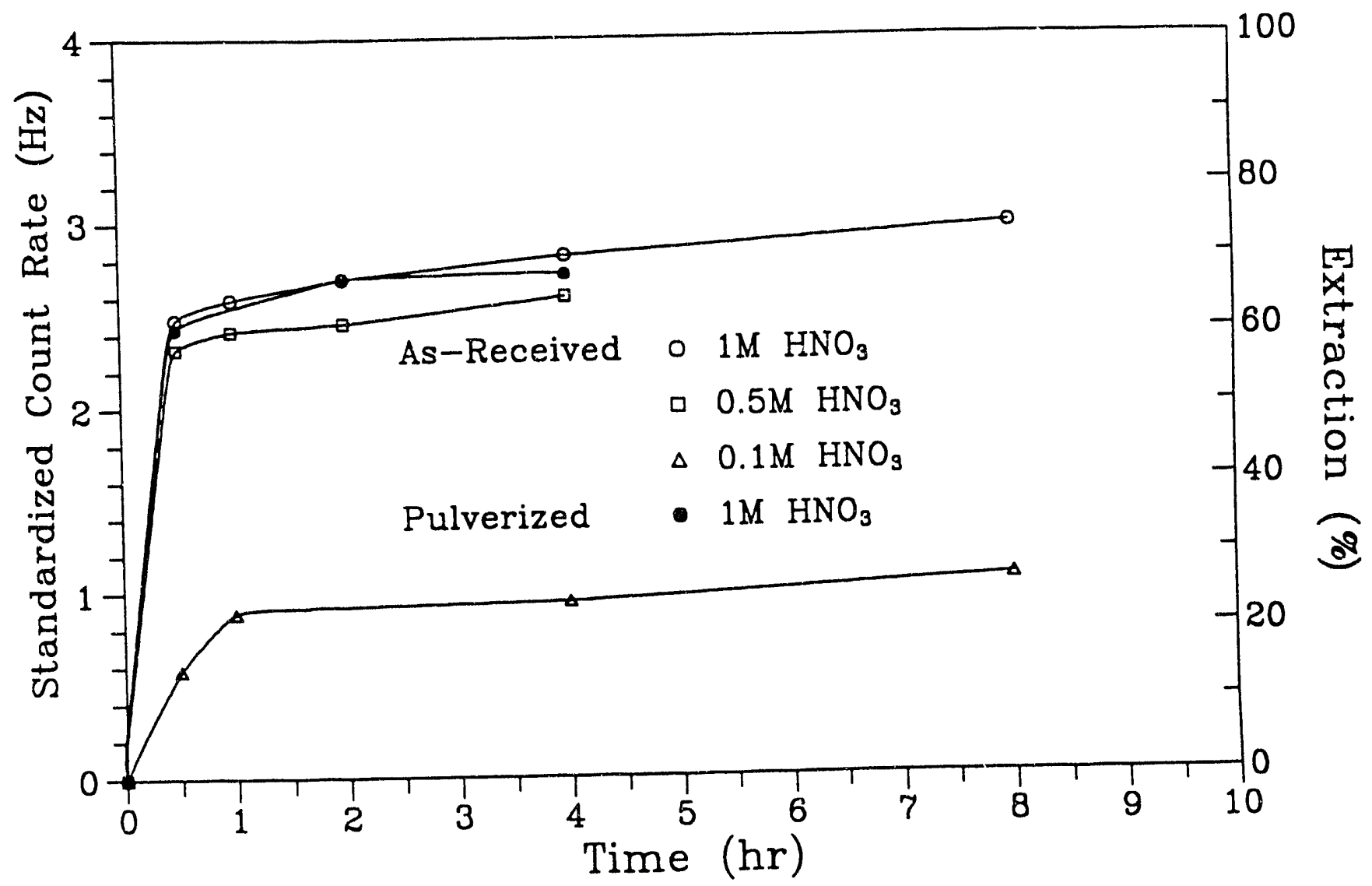

Figure 8. Standardized count rate and TRU extraction versus time for agitation-leach with $\mathrm{HNO}_{3}$ at $50^{\circ} \mathrm{C}$ and for three acid concentration levels. Solids to liquid ratio: $1 / 8$ (11 wt\% slurry). 
In Figure 9, eight replicate runs for acid concentrations of $1 \mathrm{M}$ and $0.5 \mathrm{M}$ (including those shown in Figure 8 ) are represented by the hatched region. For 4 hours leach-durations, the extractions achieved lie between a low value of $65 \%$ and a high of $80 \%$.

This variation can only be attributed to improper retrieval of the soil sample from the storage bottle. It is possible that the contents were not thoroughly mixed before removing the samples for the leach tests, and this may have been responsible for the range of extractions reported above.

2.1.3.5 Solids (Soil) Mass Accounting. Mass accounts for the agitation leach tests (1:8 solids to liquid ratio) with $1 \mathrm{M} \mathrm{HNO}_{3}$, reported above, were as follows:

1. For the 14 hours run with as-received soil: $10 \%$ soil solubilized.

2. For the 4 hour run with pulverized soil: $4.6 \%$ soil solubilized.

The percentages of soil solubilized in the replicate runs ranged between 2.1 to $4.6 \%$ for 4 hours leach-duration runs. For the replicate 48 hours percolation-leach run, $4.9 \%$ of soil was solubilized.

The iron content of the leachates from the agitation-leach runs were determined by Atomic Adsorption Spectrophotometry. The concentrations ranged from 390 to $450 \mathrm{mg} / \mathrm{L}$ A similar determination for the leachate from the replicate 48 hour duration percolation run gave $375 \mathrm{mg} / \mathrm{L}$.

A sample of the leachate that had been treated with hydrogen peroxide was evaporated to dryness. This residue was analyzed on the scanning electron microscope (SEM) by Energy Dispersive Spectroscopy. The major elements detected were iron, calcium, aluminum, potassium, and magnesium (it should be noted that the lixiviant used for this run did not contain any potassium chloride). The ratio of these elements in this residue, on a mass basis, were

$\mathrm{Fe}: \mathrm{Ca}: \mathrm{Al}: \mathrm{K}: \mathrm{Mg} \equiv 1: 0.88: 0.69: 0.24: 0.19$

This information was used in conjunction with the data on the iron contents of the leachate and the chemical compoind data on the soil ${ }^{1}$ to estimate the mass percent of the soil attributable to these sources. This estimate yielded a value of $2 \%$, and when compared with the gravimetric measurements on the leached soil, indicated a deficit that did not exceed 3\%. The exception was the 14 hours duration agitation-leach run that was $8 \%$. However, the determination for iron was not conducted on this leachate, and therefore, the comparison is invalid. For the $3 \%$ deficit cited, the discrepancy can be attributed to oxidation of organic components in the soil of which $6 \%$ is present.

2.1.3.6 Photomicrographs of As-Received/Leached Soil Particle. Two SEM photomicrographs of selected soil particles from the as-received material and from the leach residue are shown in Figures 10 and 11. In Figure 10, a quartz particle (characteristic concoidal fracture surfaces) from each of the two sources, referred to above, is shown. There does not appear to be significant leaching of the major surfaces. However, occluded entities within the particle [lower left corner of (b)] appear to have either been leached out or become dislodged. The particles shown in Figure 11 are hard agglomerates, most likely clay. The features of the particle after leaching, (b), are not strikingly different from the unleached particle. However, upon close examination, it can be seen 


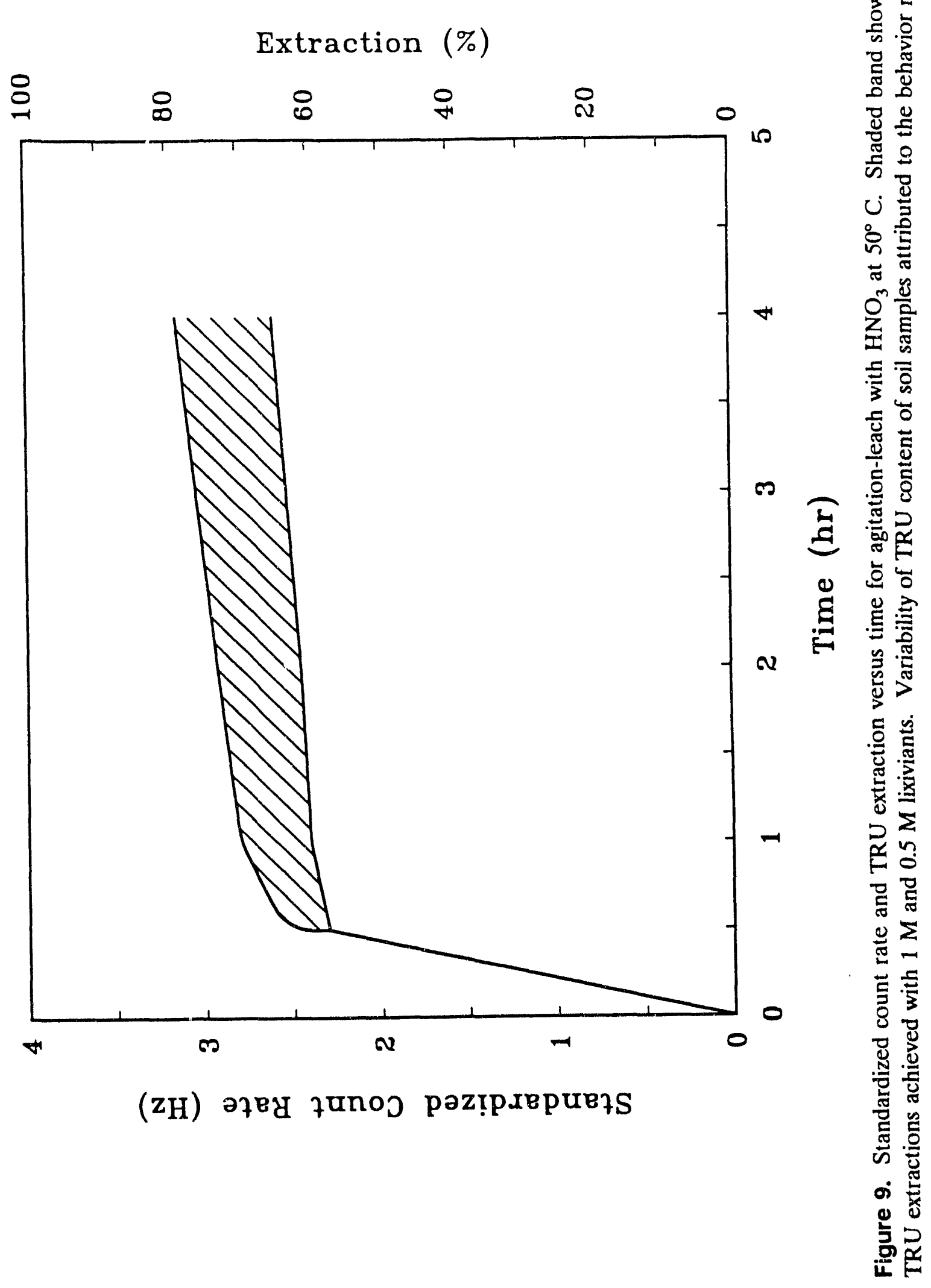


that the particle has undergone particle decrepitation, and the small entities of which this agglomerate is comprised are clearly visible within the surface.

\subsection{Coprecipitation/Adsorption Studies}

This component of the investigation was focused on the decontamination of (rejection of TRU ions from) the leachate. The use of amorphous iron-oxyhydroxide was proposed as a candidate adsorbent that would be effective for this purpose.

\subsubsection{Test Procedures}

Sodium hydroxide was added to the selected leachate to increase the $\mathrm{pH}$ to a range where the adsorbent would be stable. It was found that below a pH of 2 , at ambient temperature $\left(22-25^{\circ} \mathrm{C}\right.$ ), the iron oxyhydroxide would be solubilized. All tests were conducted at ambient temperature with the leachates from the tests performed with the nitric acid lixiviants, only. Four milliliters of leachate were placed in a $10 \mathrm{~mL}$ vial, and sodium hydroxide $(5 \mathrm{M})$ was dispensed with a $100 \mu$ pipette. Two values of $\mathrm{pH}$ were investigated, 4 and 7 . Incipient precipitation of dissolved ions, principally iron but also aluminum and calcium, occurred when the $\mathrm{pH}$ was increased to approximately 2.5 . The volume of sodium hydroxide added was approximately $350 \mu \mathrm{l}$ for the leachate from $0.5 \mathrm{M} \mathrm{HNO}_{3}$ leaching test, and $800 \mu$ l for the leac zate from the $1.0 \mathrm{M} \mathrm{HNO}_{3}$ leaching test. "ypically, between 20 to $50 \mu \mathrm{l}$ were required to effect a $\mathrm{pH}$ change from 4 to 7 ; the major portion of the addition being required to increase the $\mathrm{pH}$ to a value of 4 . A miniature magnetic stirring bar provided for agitation during these procedures. The elapse time was approximately 30 minutes. The stirring bar was retrieved and sedimentation allowed to occur over a 4-hour perind, after which $2 \mathrm{~mL}$ of supernatant liquid was withdrawn with a pipette for radioactive counting.

It was found that addition of the oxyhydroxide to the system, once the $\mathrm{pH}$ was adjusted, did not result in a significant increase in rejection of TRU ions to the solid phase present. Thus, the predominant rejection mechanism was associated with the precipitate produced in situ from the dissolved soil components.

\subsubsection{Preparation of Amorphous Iron Oxyhydroxide}

Preparation of the iron oxyhydroxide was conducted as outlined in the work by Davis et al. ${ }^{2}$ The aqueous electrolyte from which it was precipitated consisted of nitrate anions. Sodium nitrate was used to provide for an ionic strength of $0.1 \mathrm{M}$, and ferric nitrate at a concentration of $10^{-2} \mathrm{M}$ was added to the system. Precipitation of the iron was achieved by addition of carbonate-free sodium hydroxide to the system (nitrogen purged). The final $\mathrm{pH}$ of the electrolyte was approximately 7 . A photomicrograph of this reddish-brown material is included in Appendix A. The particles became agglomerated when placed on the stub used for the SEM imaging. An X-ray diffraction pattern is also included and confirms that the powder is indeed amorphous to X-rays (poorly crystallized).

\subsubsection{Preliminary Tests}

Preliminary testing indicated that incipient precipitation would occur when the $\mathrm{pH}$ had been adjusted to a value of approximately 2.5 (final $\mathrm{pH}=4$ ) with (concentrated $5 \mathrm{M}$ ) sodium hydroxide. The precipitate from the agitation-leach tests had a grayish-brown color and did not form a dense 

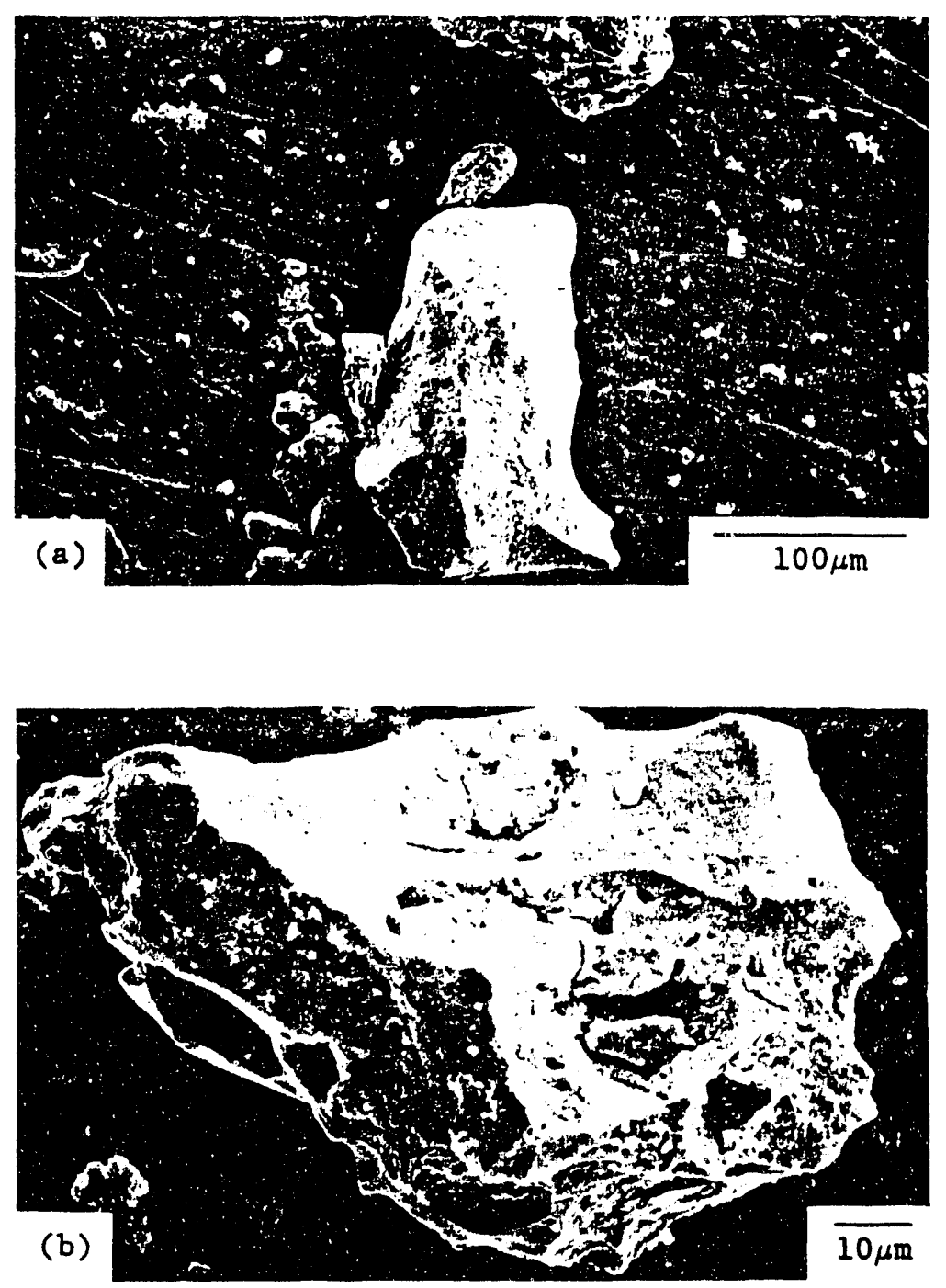

Figure 10. SEM photomicrographs comparing two (quartz) particles with similar morphological feature in (a) unleached soil and (b) the leached soil. 

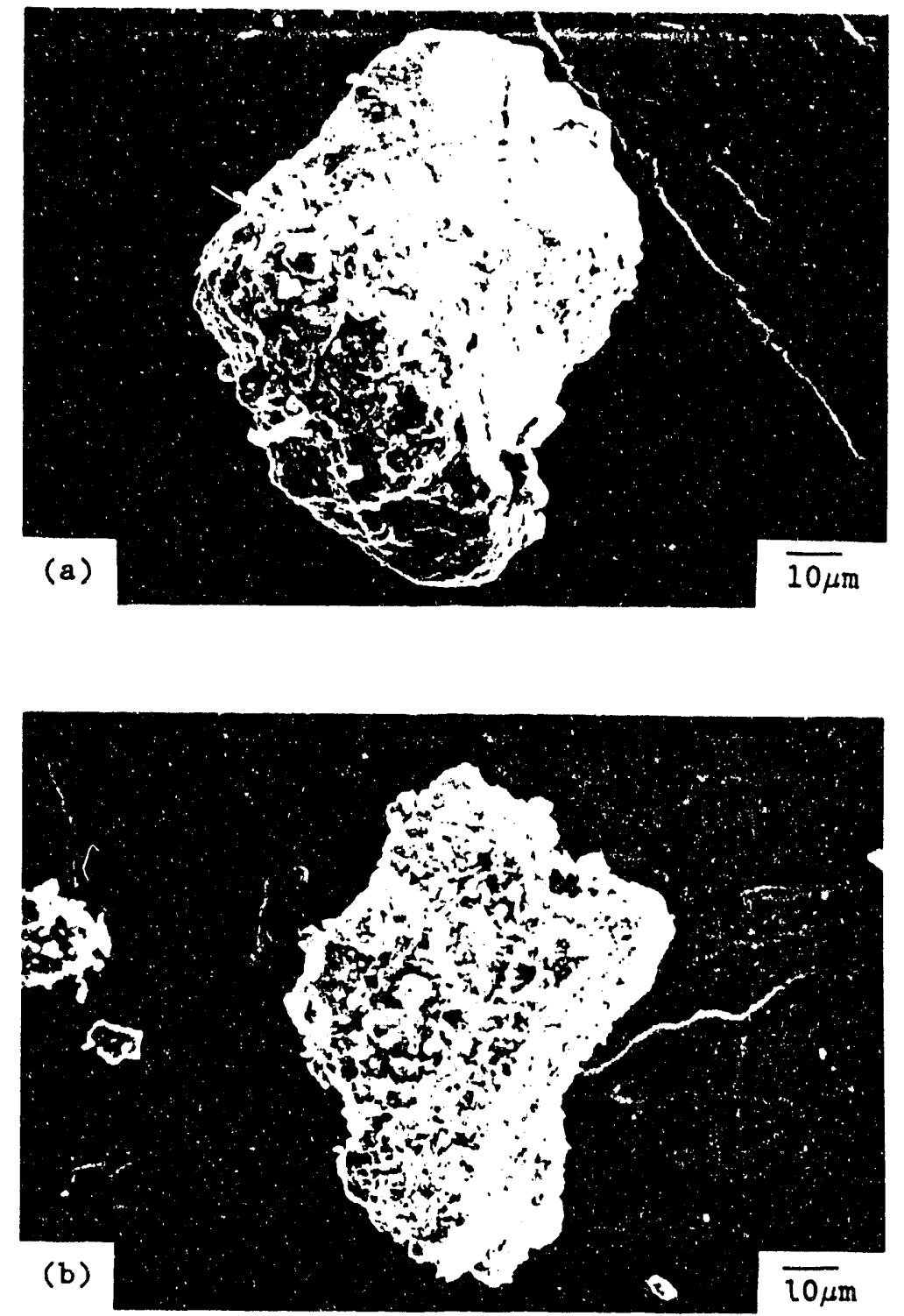

Figure 11. SEM photomicrographs comparing two (clay) particles with similar morphological feature in (a) unleached soil and (b) the leached soil. 
sediment. In one test hydrogen peroxide was added to the leachate and then boiled briefly to remove excess peroxide. This was done to oxidize the iron to the ferric form with the expectation that the precipitate would be less colloidal than the lighter brown precipitate, which had been obtained previously. It was found that a denser sediment was indeed obtained and was a darker brown color. When iron oxyhydroxide was added to either system, a mixed, dark brown, precipitate was found to settle out on the bottom of the vial. Also, it was determined that approximately $20 \%$ TRU components was rejected to the precipitaie. Typically, a leachate with a standardized count rate of $1.9 \mathrm{~Hz}$ was reduced to $1.5 \mathrm{~Hz}$.

On assessing these preliminary results anu recognizing that the TRU species in the leachate may be present at a higher valence state, it was concluded that a higher $\mathrm{pH}$ should lead to higher rejection of TRUs to the precipitate. For example, $\mathrm{Pu}^{4+}$ disproportionates to produce $\mathrm{Fu}^{3+}$ and $\mathrm{PuO}_{2}{ }^{2+}$. The principal equilibrium reaction being

$$
3 \mathrm{Pu}^{4+}+2 \mathrm{H}_{2} \mathrm{O}=2 \mathrm{Pu}^{3+}+\mathrm{PuO}_{2}^{2+}+4 \mathrm{H}^{+}
$$

Thus, if this reaction had originally occurred in the soil, the $\mathrm{PuO}_{2}{ }^{2+}$ would be present in the leach system as a metastable species since rupture of plutonium-oxygen bonds (as might be expected in a low $\mathrm{pH}$ medium, according to the reaction above) is exceedingly slow. Consequently, a higher $\mathrm{pH}$ would be required to hvdrolyze and either occlude this species in the primary precipitate or adsorb it onto the iron oxyhydroxide. This premise is based upon the relative magnitudes of the first hydrolysis constants for $\mathrm{Pu}^{4+}$ and $\mathrm{PuO}_{2}{ }^{2+}\left(10^{-0.5}\right.$ and $\left.10^{-5.6}\right)$, which indicates that at higher $\mathrm{pH}$, $\mathrm{PuO}_{2}{ }^{2+}$ shoulc be hydrolyzed and occluded/adsorbed with the in situ produced hydroxide precipitate and/or the amorphous iron oxyhydroxide. Indeed, it was discovered that upon increasing the $\mathrm{pH}$ of the hydrogen peroxide treated leachate to a value of 7 greater than $90 \%$ rejection to the precipitate was achieved. Typically, the leachate with a standardized count rate of $1.9 \mathrm{~Hz}$ was reduced to $0.13 \mathrm{~Hz}$.

\subsubsection{Validation Tests}

Two series of validation tests were performed. The treatment scheme for each series is depicted in Figure 12. The primary leachate was treated by four possible routes:

1. The $\mathrm{pH}$ of the leachate was adjusted to a value of 4. After sedimentation, the supernatant $(2 \mathrm{~mL})$ was subjected to radioactive counting.

2. The same as 1 , but the supernatant is treated with iron oxyhydroxide (approximately $0.005 \mathrm{M}$ ). After sedimentation, $2 \mathrm{~mL}$ of supernatant was subjected to radioactive counting. It was discovered that if the iron oxyhydroxide was added to the overall system (i.e., including the in situ produced precipitate), no significant difference in behavior was observed. This was also true for the route where the $\mathrm{pH}$ of the system was adjusted to a value of 7 .

3. The same as 1 , but the $\mathrm{pH}$ is adjusted to a value of 7 .

4. The same as 2 , but the $\mathrm{pH}$ is adjusted to a value of 7 . 


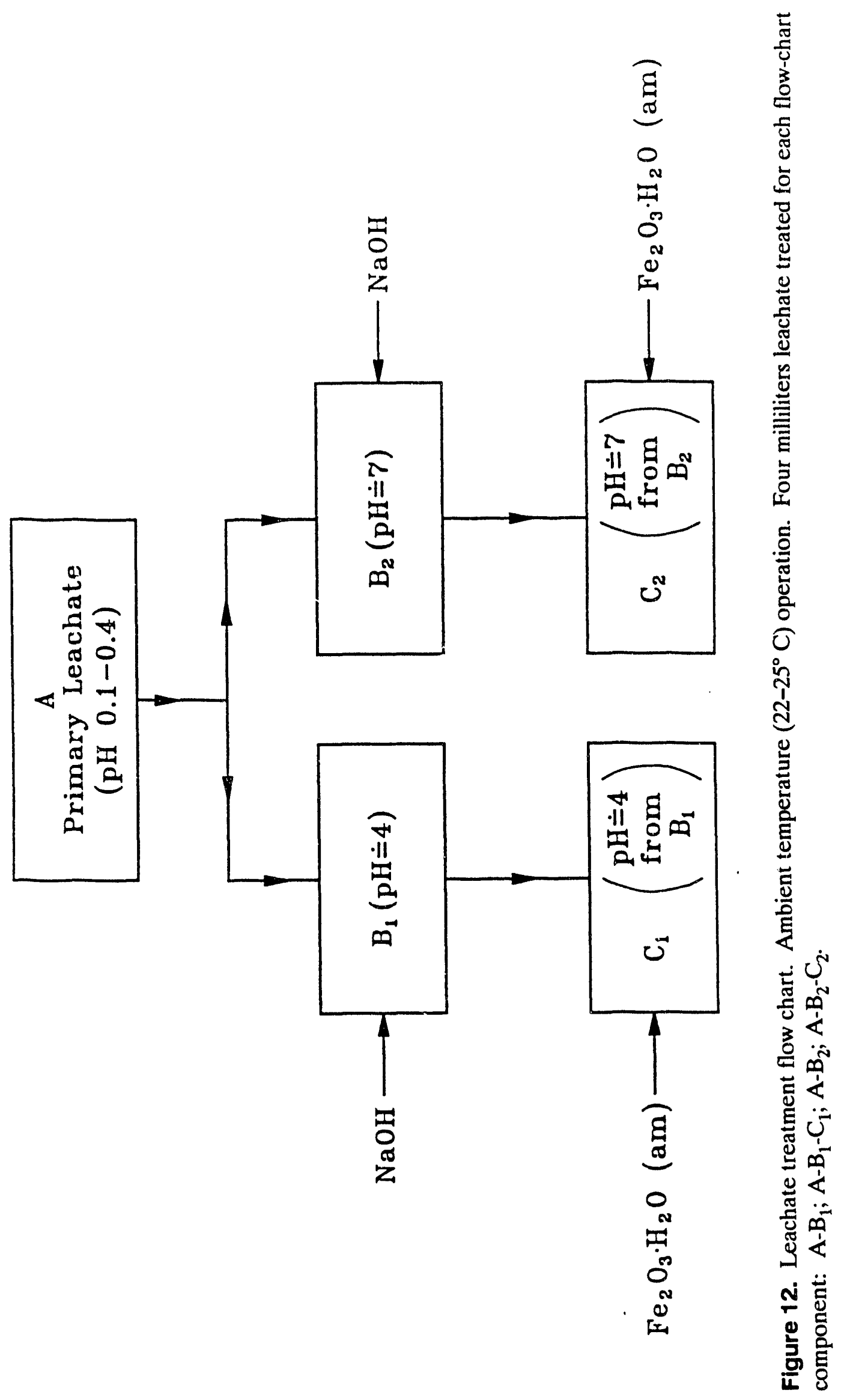


The results of the two series of tests for the four treatment routes are shown in the Figures 13 and 14. The significance of the ordinate on the right is that $100 \%$ would correspond to a leachate for which all the TRU components in the soil had been solubilized. However, the solids to liquid ratio would determine the concentration to which they would be present-higher in a 1:2 ratio than a $1: 8$ ratio. In Figure 13, the results depicted are for the leachate that had been treated with hydrogen peroxide (1:8; solids:liquid ratio). The original standardized count rate was $3.2 \mathrm{~Hz}$. Rejection to the in situ precipitate when the $\mathrm{pH}$ was adjusted to a value of 4 decreased the count rate to $2.1 \mathrm{~Hz}$ (34\% reduction). Addition of the iron oxyhydroxide produced a further decrease to $1.6 \mathrm{~Hz}$ (50\% reduction). The corresponding behavior for the two routes, where the $\mathrm{pH}$ of the leachate was adjusted to a value of 7 , decreased from $3.2 \mathrm{~Hz}$ to $0.1 \mathrm{~Hz}$ (97\% reduction), and when iron oxyhydroxide was added, the standardized count rate decreased to $0.05 \mathrm{~Hz}$ (>97\% reduction).

The results for similar treatments applied to the leachate from the percolation leach test (1:8; solids:liquid ratio) that produced 93\% extraction (see Section 2.1.3) are shown in Figure 14. Here the original standardized count was $3.8 \mathrm{~Hz}$. The treatment steps for the route that used a pH of 4 adjustment produced treated leachates with count rates of 2.9 and $2.4 \mathrm{~Hz}$ (17 and $36 \%$ reduction); the larger reduction corresponding to the route that included the iron oxyhydroxide addition. The behavior for the treatment steps that used a $\mathrm{pH}$ of 7 was indistinguishable from the corresponding results for the first series. In fact, the count rates for the treated leachate coincided with the detection limit for the radioactive counting system as imposed by the variability in the background counts. Increased sensitivity would have required that a (10 times) larger sample be treated and subsequently concentrated, also by a factor of ten, by evaporation of the water in the sample. 


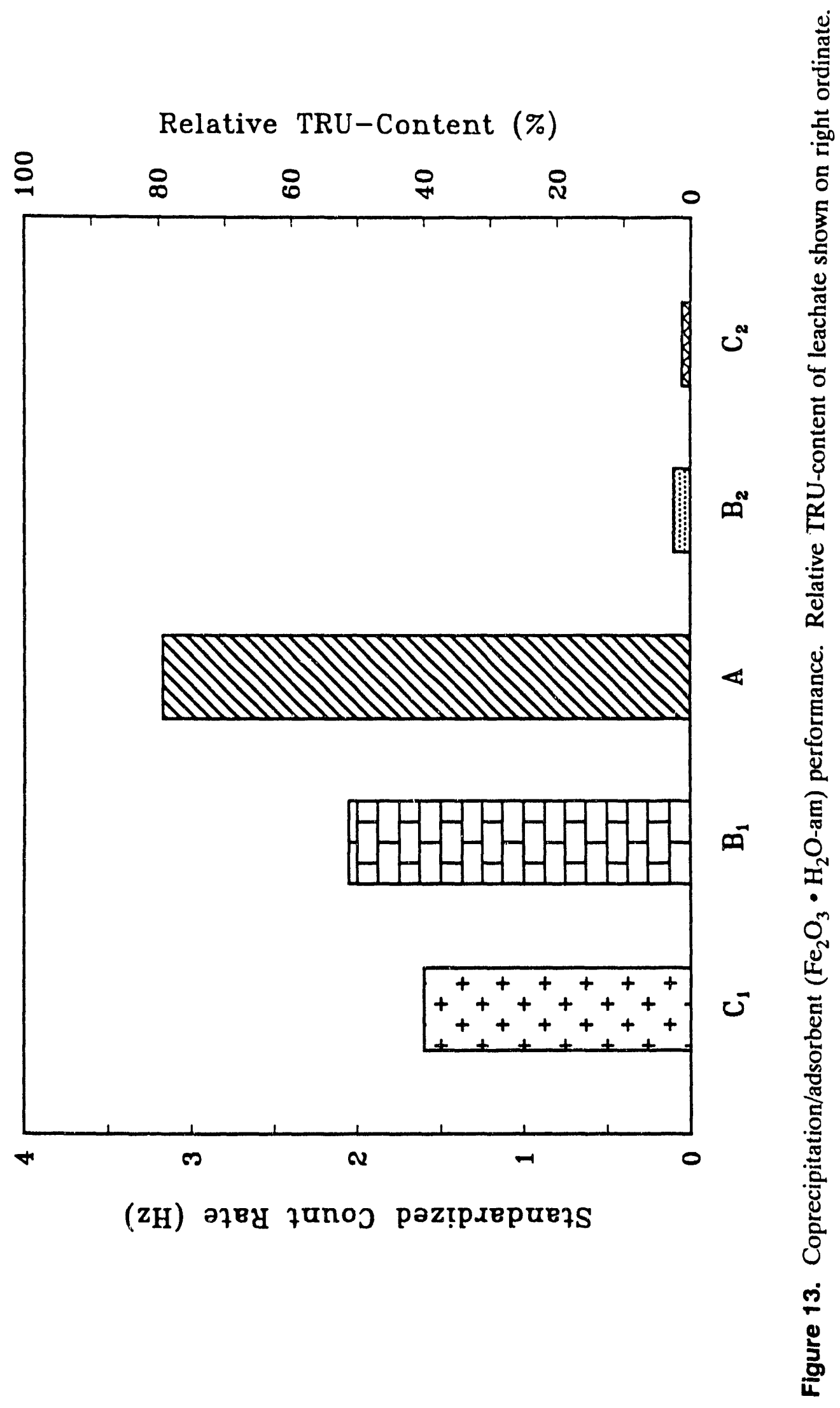




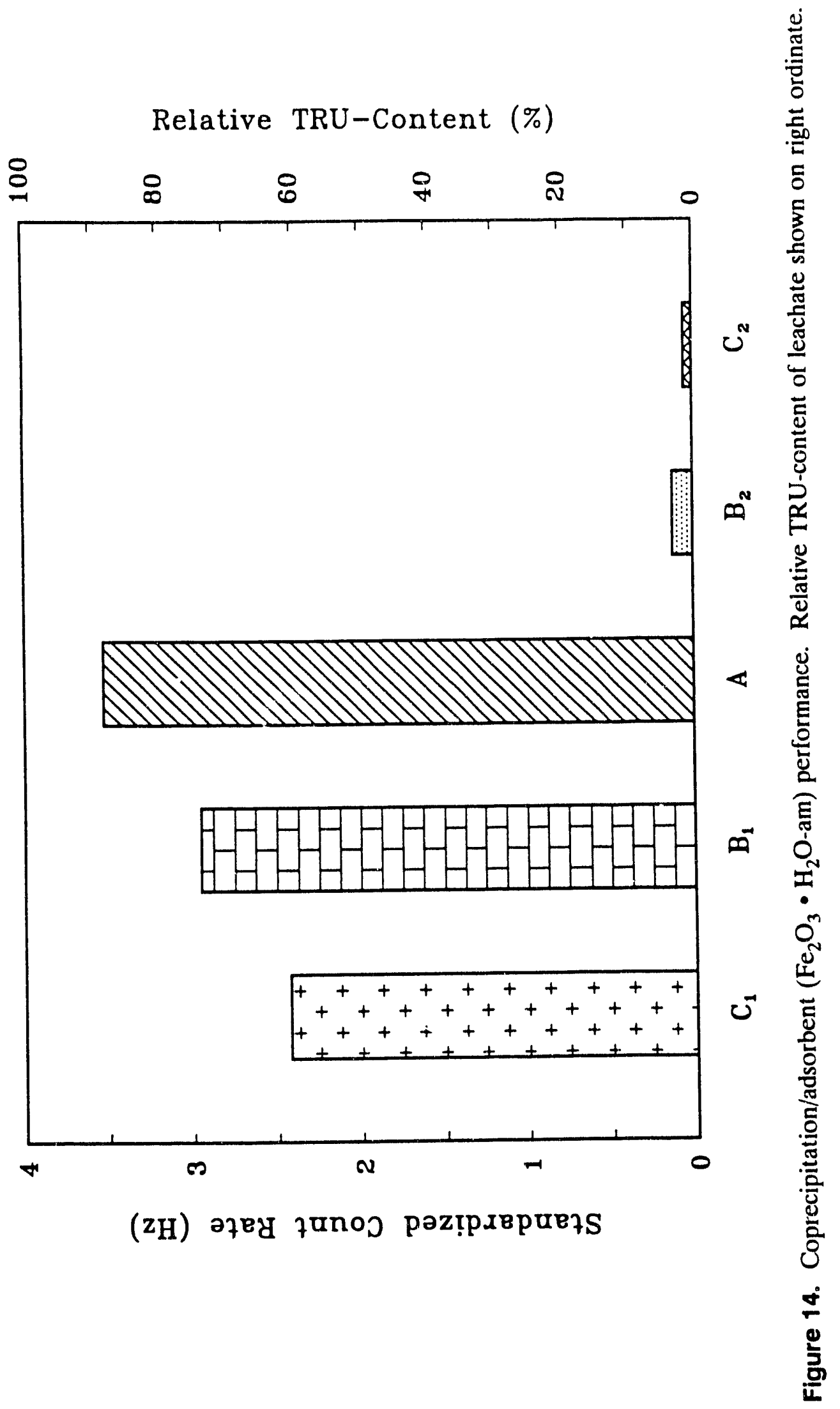




\section{CONCLUSION}

In this section, a summary of the salient information obtained from the work conducted is provided and followed by enumerated conclusions and recommendations.

\subsection{Summary}

Aqueous phase leaching of TRU-contaminated soil (Rocky Flats) appears to be a viable option and worthy of serious consideration in the development of remediation technology. Lixiviants based on hydrochloric, sulfuric, or nitric acids have been shown to provide TRU extractions that are similar. Validation runs, conducted with nitric acid, produced extractions in the 65 to $80 \%$ range for a 4-hour duration agitation-leach. Extraction by percolation leaching for 48 hours was approximately $75 \%$. Soil losses to the leachate did not exceed $5 \mathrm{wt} \%$ when percolation leaching was employed. Also, the major contribution to this loss appears to be from the organic components in the soil.

Stripping of the TRU ions in the leachate by adding sodium hydroxide to increase the $\mathrm{pH}$ was successfully demonstrated. Rejection of these species to the in situ precipitate formed at a $\mathrm{pH}$ of 7 was less than the detection limit available by radioactive counting. The use of amorphous iron oxyhydroxide appears to be marginal, but because of the detection limitations ailuded to above, a definitive evaluation is not possible from the results of this study.

\subsection{Conclusions and Recommendations}

The following conclusions are enumerated to highlight the significant aspects of the work conducted. Recommendations are provided for further elucidation studies that would significantly contribute to the general data base on this soil remediation strategy. An appraisal of the remediation technique is then stated.

1. Leaching of TRU-contaminated soils with acids, in the concentration range (0.5 to $1 \mathrm{M}$ ), can provide satisfactory extraction of these components from the soil. Soil losses to the leachate should not exceed 5\% for soil types (primarily silicates) similar to the Rocky Flats sample.

2. Leachates can be effectively stripped of TRU ions by $\mathrm{pH}$ adjustment to a value of 7 . Amorphous iron oxyhydroxide may provide for lower residual TRU ions in the treated leachate.

It is recommended that additional work be performed to

1. Provide an overall evaluation of the remediation scheme for a sulfate based system (sulfuric acid lixiviant)-since this is likely to be less expensive than the nitrate system. Stripping of the leachate with amorphous iron oxyhydroxide confined the present study to a nitrate based system. However, it is conceivable that the efficacy of this adsorbent may not be impaired when it is introduced into a sulfate system. More so, when one considers that it is likely to be used in a scavenging role. 
2. Develop the use of a flocculent (most likely an anionic type) to provide for thickening and disengagement of the precipitate from the supernatant of the treated leachates.

Based on the results obtained during this study, the overall appraisal of the remediation technique leads to the recommendation that it is worthy of development on a pilot-plant scale. 


\section{REFERENCES}

1. Jae-Ho Lee and G. P. Martins, Characterization Studies on: A) Contaminated Batch of Rocky Flats Soil; B) Uncontaminated Batch of INEL Soil, final report on work conducted for EG\&G Idaho, P.O. \# C91-132995, 1991. Also issued Characterization Studies on: A Contaminated Batch of Rocky Flats Soil, B) Uncontaminated Batch of INEL Soil, EGG-WTD-9749, 1991.

2. J. A. Davis, and J. O. Leckie, J. Coll. Interface Sci., 67, 1978. 


\section{Appendix A}

\section{Amorphous Iron Oxyhydroxide Characterization \\ - SEM Photomicrograph \\ - X-ray Diffraction Pattern}




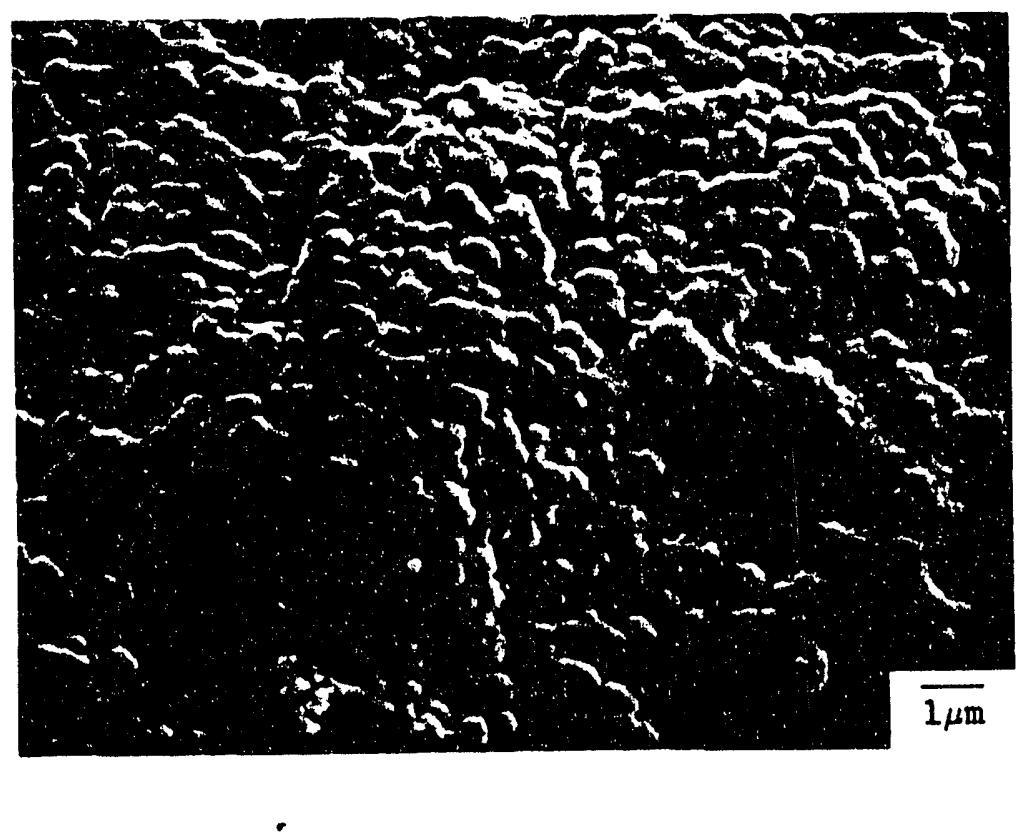

Figure A-1. SEM photomicrograph of agglomerated amorphous iron oxyhydroxide as prepared by the procedure described in Section 2.2.2. 


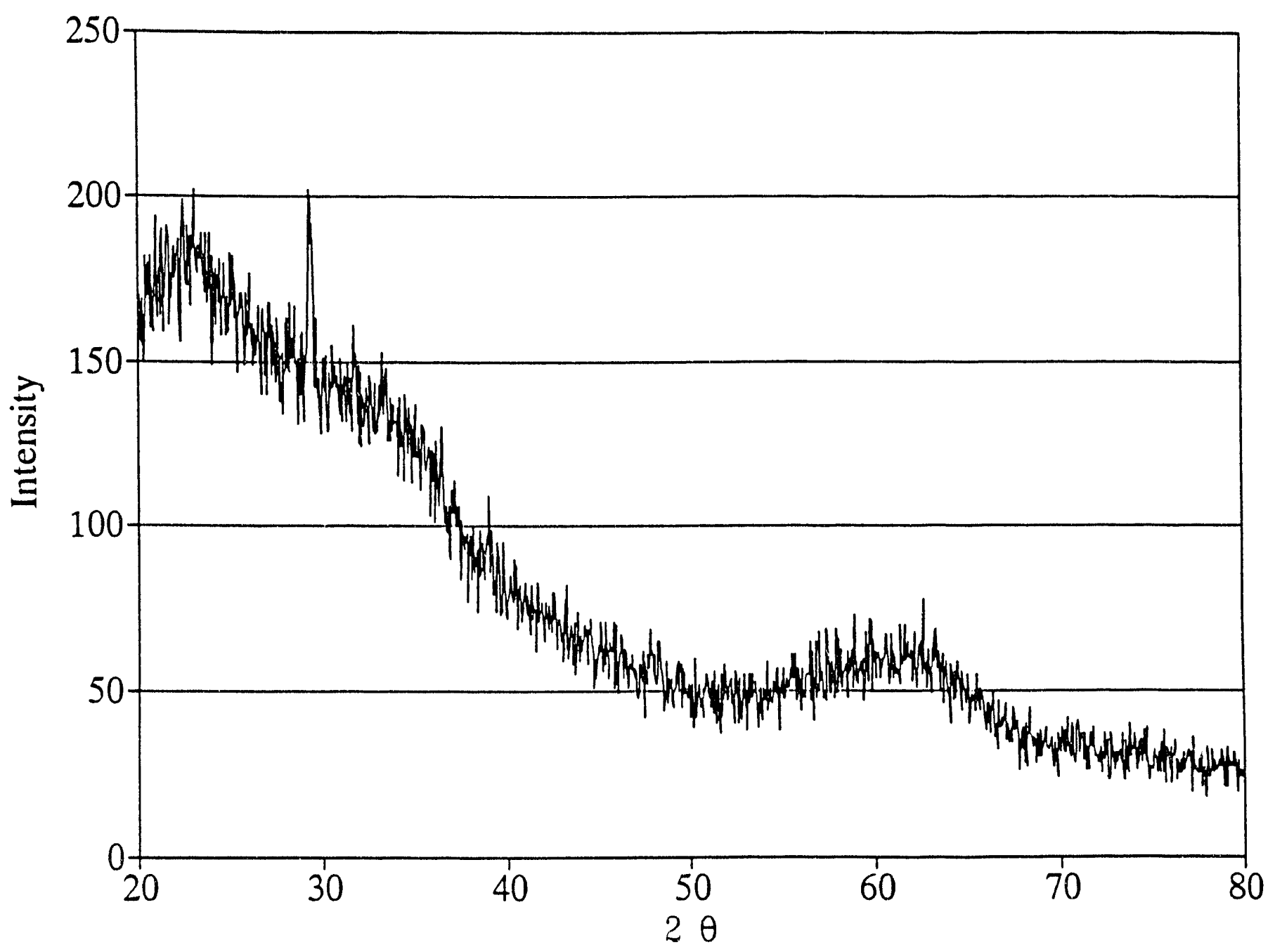

Figure A-2. X-ray diffraction pattern for the amorphous iron oxyhydroxide. 

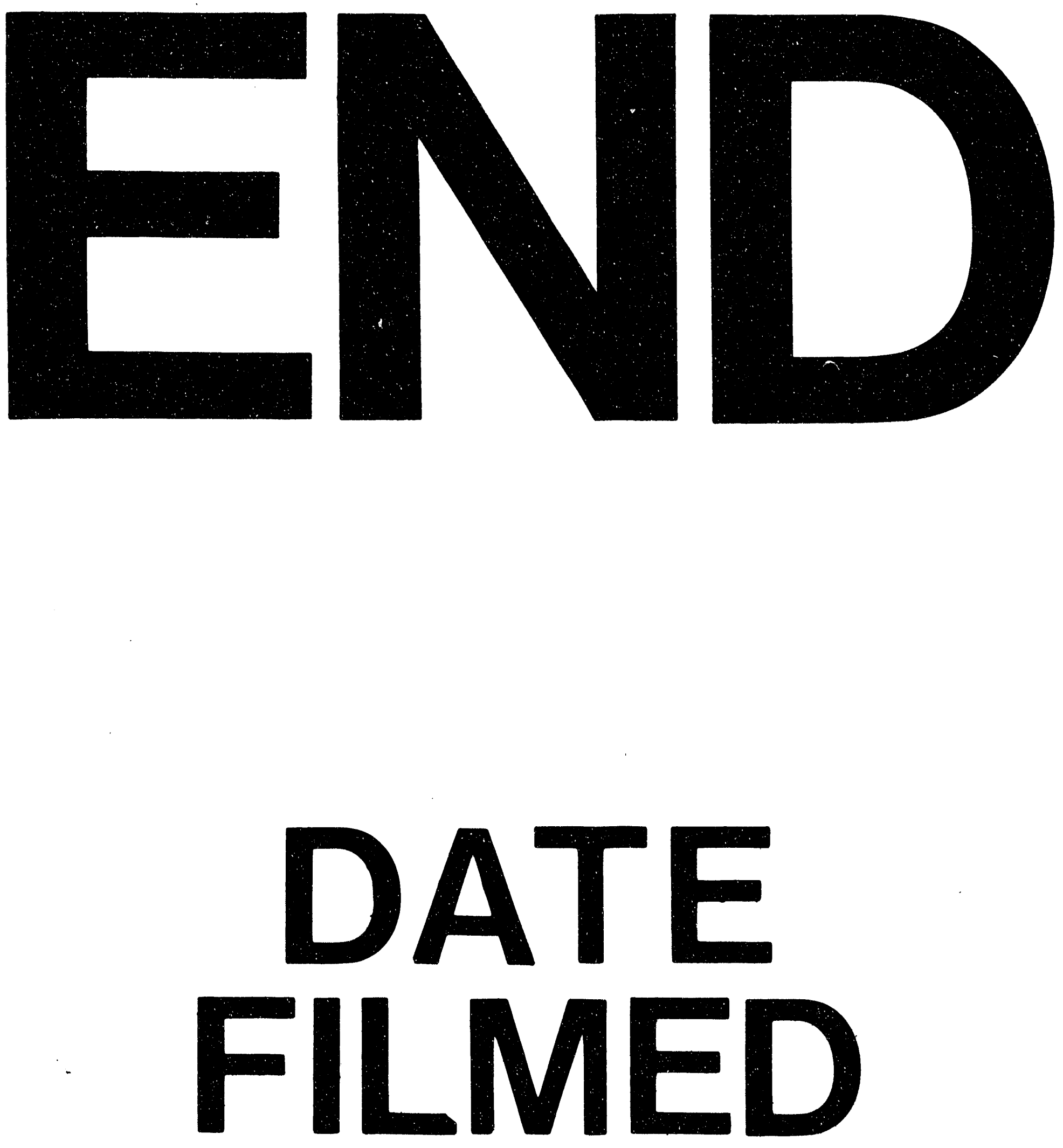

1

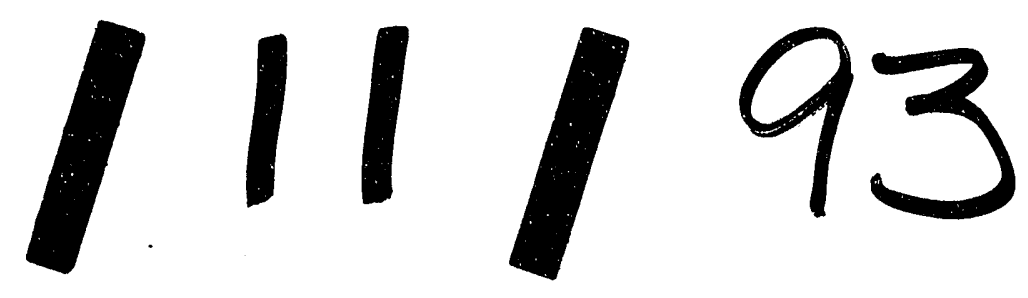


